\title{
Cross-border Effects of Capacity Remuneration Mechanisms: The Swiss Case
}

By Florian Zimmermann, Andreas Bublitz, Dogan Keles, Wolf Fichtner

No. 35 | February 2019

\section{WORKING PAPER SERIES IN PRODUCTION AND ENERGY}

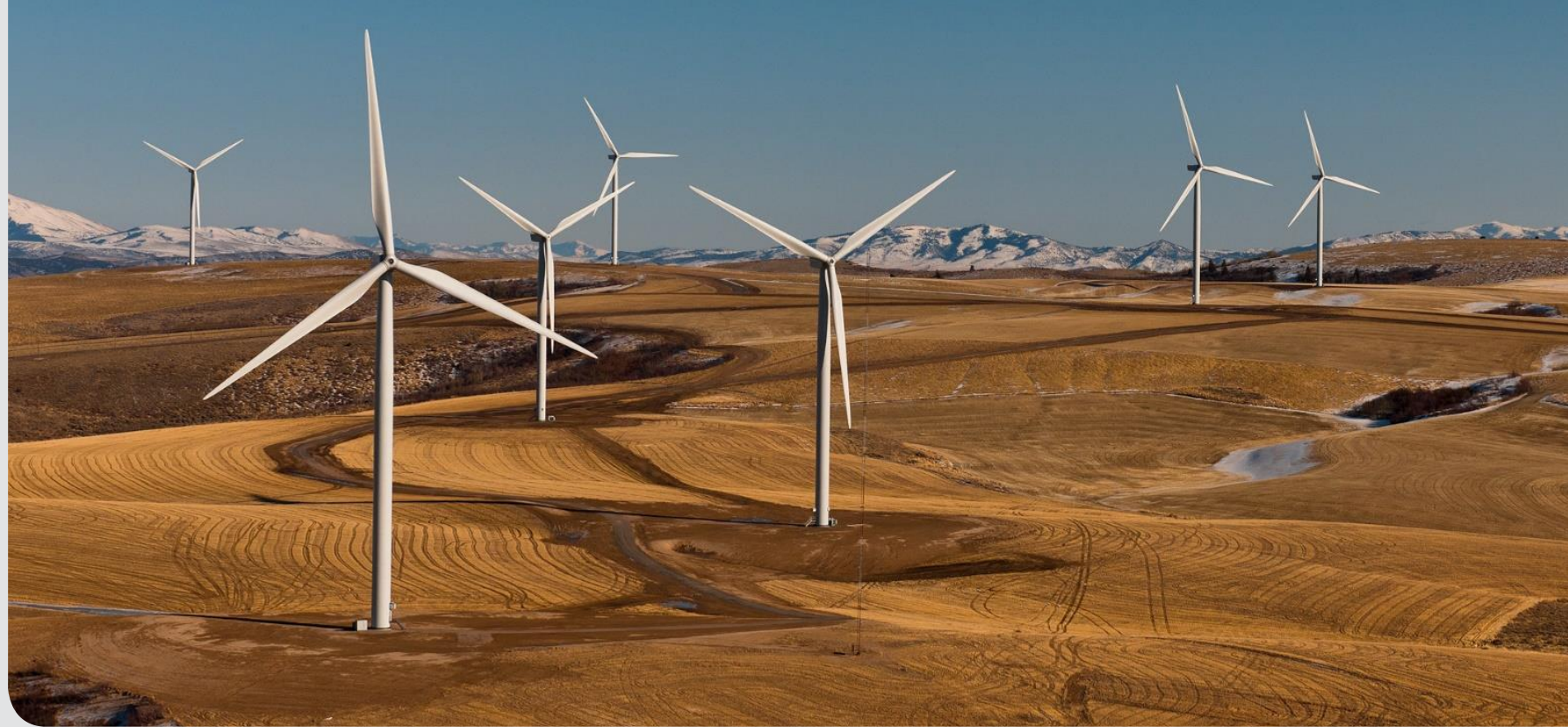




\section{Cross-border Effects of Capacity Remuneration Mechanisms: The Swiss Case}

\section{Florian Zimmermann*, Andreas Bublitz, Dogan Keles, Wolf Fichtner}

Chair of Energy Economics, Institute for Industrial Production (IIP), Karlsruhe Institute of Technology (KIT), Hertzstraße 16, 76187 Karlsruhe, Germany

*Corresponding author. Email: florian.zimmermann@kit.edu Tel.:+4972160844580

In this article, cross-border effects of different market design options are analyzed using Switzerland as a case study, which is strongly interconnected to larger neighboring markets. An investigation is conducted with an agent-based model where in one scenario all market designs are represented according to the current legislation, and in another, energy-only markets (EOM) are assumed in all considered countries. The results show that wholesale electricity prices are highly dependent on the chosen market design and in the annual average up to $27 \%$ higher in the EOM scenario. Due to expected larger interconnector capacities, this increase is evident in all simulated markets. Further, the results indicate that the planned market design changes in the neighboring countries decrease investments in Switzerland. However, generation adequacy is still guaranteed due to the high Swiss hydropower storage capacity. Our results suggest that, under the current circumstances, a domestic mechanism in Switzerland is not required.

The picture on the front page was taken by Douglas Barnes https://www.flickr.com/photos/departmentofenergy/7795441536/ 


\title{
Cross-border Effects of Capacity Remuneration Mechanisms: The Swiss Case
}

\author{
Florian Zimmermann ${ }^{\mathrm{a}, *}$, Andreas Bublitz ${ }^{\mathrm{a}}$, Dogan Keles ${ }^{\mathrm{a}}$, Wolf Fichtner ${ }^{\mathrm{a}}$ \\ ${ }^{a}$ Karlsruhe Institute of Technology (KIT), Chair of Energy Economics, \\ Hertzstraße 16, D-76187 Karlsruhe
}

\begin{abstract}
In this article, cross-border effects of different market design options are analyzed using Switzerland as a case study, which is strongly interconnected to larger neighboring markets. An investigation is conducted with an agentbased model where in one scenario all market designs are represented according to the current legislation, and in another, energy-only markets (EOM) are assumed in all considered countries. The results show that wholesale electricity prices are highly dependent on the chosen market design and in the annual average up to $27 \%$ higher in the EOM scenario. Due to expected larger interconnector capacities, this increase is evident in all simulated markets. Further, the results indicate that the planned market design changes in the neighboring countries decrease investments in Switzerland. However, generation adequacy is still guaranteed due to the high Swiss hydropower storage capacity. Our results suggest that, under the current circumstances, a domestic mechanism in Switzerland is not required.
\end{abstract}

\footnotetext{
*Corresponding author

Email address: florian.zimmermann@kit.edu (Florian Zimmermann)
} 


\section{Research highlights}

- CRMs are an effective instrument to increase domestic generation adequacy.

- CRMs in neighboring countries result in less investments in the Swiss market.

- Swiss generation adequacy is secured by a large storage capacity without an own CRM.

- Electricity prices in all countries strongly increase with and without CRMs.

Keywords: Capacity remuneration mechanisms, Cross-border effects, Electricity market coupling, Generation adequacy, Switzerland, Agent-based modeling 


\section{Introduction}

European electricity markets are becoming more and more integrated as a consequence of the internal market guidelines and the so-called Energy Union strategic framework of the European Commission (1997, 2003, 2009). The integration of the electricity markets is mainly driven by two intertwined processes: On the one hand, European markets are more tightly linked by implicit auctions and combined by the so-called Price Coupling of Regions run by eight European power exchanges (EPEX SPOT, 2018b). On the other hand, the physical transmission grid is expanded, and in particular, the interconnectors will be further enhanced according to the Ten Year Network Development Plan of the European Network of Transmission System Operators (ENTSO-E, 2018a).

As a result, different cross-border effects can be observed: e.g., market clearing is determined in a way that energy flows from market areas with higher prices to those with lower prices resulting in a convergence of electricity prices in connected market areas given that sufficient interconnection capacity is available. The price convergence stops if the available interconnector does not allow a further flow of electricity and, in this case, a certain price difference remains. However, an additional interconnection line between two market zones can increase the price assimilation resulting in positive welfare effects (Ringler et al., 2017).

In the case of a small country neighbored by large markets (asymmetrical market areas), the cross-border price effect can be strong. Therefore, as a case study, Switzerland serves as a useful example for analyzing the impact of large neighboring markets on a smaller one. Because the analysis by 
Dehler et al. (2016) shows a strong interdependence of wholesale electricity prices of Switzerland and its neighbors (Austria, France, Italy, and Germany) due to a tightly connection between the electricity grids. For instance, the electricity price decline between 2011 and 2016 in the Central Western European countries driven by a renewable expansion and low prices for EU ETS emission allowance resulted in lower prices also in the Swiss electricity market. This price decline can be welcomed from the consumer perspective but has a lowering effect on producer rent and the profitability of power plants (Bublitz et al., 2017; Hirth, 2018; Kallabis et al., 2016). This might yield not only for thermal capacities but also for the dominant hydropower plants in Switzerland.

These developments are expected to intensify in the near future, as some neighboring countries changed the design of their wholesale electricity markets in the past few years, which can put additional pressure on Swiss wholesale electricity prices. For instance, Germany is planning to introduce a strategic reserve (SR) to ensure generation adequacy in scarcity times (BMWi, 2017). Also, France implemented a capacity remuneration mechanism (CRM), a decentralized capacity market, to ensure generation adequacy and incentivize demand-side management (DSM) measures in peak load times (Bublitz et al., 2018). As the yearly traded volume in the French and German electricity markets is considerably larger than in other European markets, their decisions strongly influence the neighboring markets, especially the comparatively small ones. In this context, the question arises as to whether the Swiss market also requires new instruments to ensure longterm generation adequacy by incentivizing national (re-)investments. 
Therefore, the goal of this study is to investigate the cross-border effects of CRMs on electricity prices, investments, and thus on the long-term generation adequacy in such connected market areas by applying a power market model based on agent-based simulation using Switzerland as a case study. This approach allows the consideration of individual decisions of market players and the analysis of market equilibria based on these decisions.

The remainder of the paper is structured as follows: Section 2 summarizes the current literature on cross-border effects with regard to CRMs and deduces the research gap in this context. Section 3 describes the applied simulation approach focusing on modeling CRMs in an electricity market model. The results, including investments, price impact, and the generation adequacy, are discussed in Section 4. Finally, in Section 5, the methodology is critically evaluated, and the main conclusions as well as policy implications are derived in Section 6 .

\section{Literature review}

One of the difficulties encountered in the analysis of cross-border effects is the large number of possible influences, such as the number and the market size of the countries considered. In addition, the levels of competition and the respective market designs can influence the results (Meyer and Gore, 2015). Thus, it is difficult to derive general conclusions. This fact might serve as an explanation of why the literature predominantly focuses on a single market scenario, and the research on spillover effects of capacity remuneration mechanisms is lagging behind (Lorenczik, 2017). However, without a sound theoretical framework on cross-border effects, ensuring generation adequacy 
at a regional level in an efficient manner remains a major challenge Glachant et al., 2017). This is further complicated by the fact that cross-border effects can emerge in a non-linear manner (Boffa et al., 2010).

A question frequently examined in the literature is whether free-riding occurs if a neighboring country introduces a CRM. For example, Bhagwat et al. (2014, 2017) study cross-border effects in two symmetrical market areas differing only in their design. Whereas an EOM does not limit the effectiveness of the neighboring capacity market or SR, vice versa, two effects can be observed: On the one hand, the consumers in the EOM are free-riding on the consumers in the neighboring market where a CRM is implemented. On the other hand, the dependence of the EOM on the neighboring markets is increasing. Similarly, Meyer and Gore (2015) find that the unilateral implementation of a CRM, either in the form of reliability options or a SR, weakens investment incentives in the neighboring market. Cepeda and Finon (2011) analyze the cross-border effects of three different market designs (EOM, price-capped EOM, forward capacity market). They find that in the long-term, the market area with an EOM does not benefit from the adjacent market area where a price-capped forward capacity market is implemented, and even negative externalities can arise in the form of a higher average price and lower reliability.

Lorenczik (2017) observes that the negative effect of price caps intensifies if a market is connected to neighboring markets and, thus, generation capacity and welfare further decrease. Yet, vice versa, national price caps do not seem to have a significant adverse effect on neighboring countries. Contrary to other studies, it is claimed that capacity payments do not exert a 
significant positive effect on the security of supply in neighboring countries.

Not only between a market with and without a CRM, spillover effects can occur, but also between markets with different CRMs. In a scenario where a SR is introduced in one market and a capacity market in the other, Bhagwat et al. (2014, 2017) observe negative spillover effects of the capacity market on the SR resulting in, e.g., a lower reserve margin in the market with the SR. Elberg (2014) investigates two symmetrical market areas in which either a SR or capacity payments have been implemented. On an isolated basis, both mechanisms lead to an efficient outcome. However, in a combined evaluation, the SR shows worse results due to redistribution effects, as the consumer welfare decreases in the area of the SR, whereas it increases in the adjacent area.

In some cases, CRMs are also investigated in real-world case studies. For example, Ochoa and Gore (2015) investigate the welfare and security of supply in the Finnish electricity market under consideration of potential benefits and risks arising from the connection to the Russian market. In case the electricity imports from Russia were reliably available, the expansion of transmission capacities would be recommended. However, as their reliability is doubtful, it is recommended to build up national generation capacities and maintain a SR. In another analysis, Ochoa and van Ackere (2015b) examine cross-border effects in Colombia-Ecuador and France-Great Britain. They conclude that the potential benefits are strongly linked to market complementarity and that policy measures to exploit these benefits without distorting market signals must be carefully evaluated, especially if large seasonal storage capacities exist, which might be used extensively during shortage situations 
in the neighboring country and subsequently are unavailable for national usage. In a follow-up study, Ochoa and van Ackere (2015a) once again analyze the markets of Colombia-Ecuador and find that the relative market sizes and the size of transmission capacities have a significant influence on potential cross-border benefits.

One of the remaining key challenges in evaluating generation adequacy is to assess the contribution of neighboring countries in order to avoid over- or undercapacity. Mastropietro et al. (2015) investigate possibilities to remove barriers preventing foreign participants in Europe from participating in external capacity mechanisms without reducing the short-term efficiency of the electricity market. They propose that capacities should be procured via zonal auctions, which take into account the maximum transmission capacity of the interconnection, and that capacities should not be allowed to participate in different national CRMs. Finon (2014) investigates the differences between explicit and implicit cross-border participation. In the long term, he states that excluding cross-border participants does result in neither a significantly lower efficiency nor a distortive effect on the competition. From a European perspective, however, the explicit consideration of capacities can be advantageous. Furthermore, it can be noted that the introduction of a CRM in a neighboring country considerably increases the pressure to introduce a national mechanism, in order to protect the market against possible harmful consequences (Bhagwat et al., 2017; Gore et al., 2016). Another possibility is to focus on supranational coordination (Hawker et al., 2017; Osorio and van Ackere, 2016, Neuhoff et al., 2016).

At this point, it needs to be emphasized that the uncoordinated intro- 
duction of CRMs in a tightly interconnected continental electricity system, such as the European system, can distort price signals and even impair the security of supply in a neighboring market. However, despite existing research, cross-border effects of CRMs have not yet been fully explored and, in particular, the impact on tightly connected real-world markets remains to a large extent unknown. Therefore, to deepen the understanding and identify adverse cross-border effects of CRM, a case study is carried out, in which the Swiss electricity market is analyzed. The Swiss market has two unusual characteristics that make it particularly suitable for the analysis: On the one hand, as a small market, it is strongly influenced by large neighboring markets (Dehler et al., 2016) and, on the other hand, it possesses mainly complementary and opportunity cost-based generation technologies, i.e., a significant share of hydro storage capacities (Swiss Federal Office of Energy, 2018a). As the opportunity costs are often based on results from neighboring markets, the cross-border influence is particularly strong.

\section{The agent-based modeling approach}

In this section, the methodology for analyzing the cross-border effects of different market designs is presented. To this end, an agent-based simulation model with the focus on Switzerland and adjacent countries has been developed further and applied (Section 3.1 3.3). Section 3.4 outlines the modeling of CRMs that are newly introduced or have already been implemented in the considered market areas. In order to take into account the specific characteristics of the Swiss electricity market, extensions had to be made in particular for hydropower plants, which are presented in Appendix A. 


\subsection{Overview}

In order to model the regarded electricity markets, an agent-based simulation approach is used and extended (e.g., Ringler et al., 2017). To analyze electricity markets in a dynamic environment, agent-based simulation has already been applied widely (Ventosa et al., 2005; Weidlich and Veit, 2008; Guerci et al., 2010) as it offers the possibility of integrating the individual market participants with a high level of detail (Tesfatsion, 2003). The behavior of the agents can be best described with the concept of bounded ra-

tionality (Simon, 1986), which states that all decisions are made on the basis of the agents' limited knowledge about the present and imperfect information about the future. Therefore, the result of the model is not a long-term, optimal equilibrium determined by a central decision-maker, but depends on the decisions of all agents, who pursue individual strategies to reach their goals. Thereby, the market development under consideration of the complex interactions can be investigated even in non-equilibrium situations, and new insights can be gained (Epstein, 1999). For instance, this also means that the demand may not be met by the supply capacity as agents can invest less than the required capacity in the case of an expected negative net present value (NPV) of new investments. Besides, it is also possible for power plant operators to submit strategic bids above the variable costs.

In the applied agent-based bottom-up simulation model, individual agents are major national and international actors representing the main generation companies. The model integrates the short-term dispatching of generation units with an hourly time resolution (Section 3.2) and the long-term capacity planning with regard to conventional power plants (Section 3.3). A schematic 


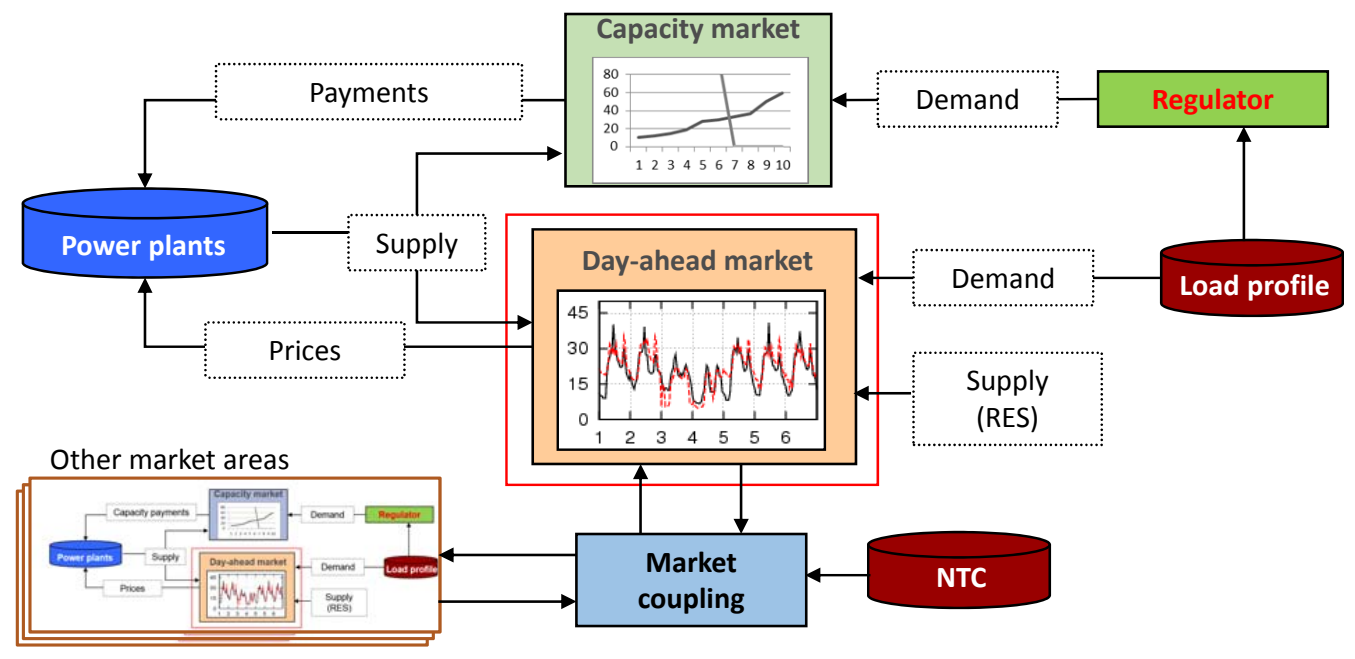

Figure 1: Schematic overview over the agent-based simulation model. The different modules such as day-ahead market, capacity market and market coupling are presented. Also the main input data, i.e., load profiles, power plants and net transfer capacities (NTCs) are shown.

overview of the model is illustrated in Figure 1.

\subsection{Day-ahead market}

In order to analyze in particular the interactions of the different market areas, each market is implemented as an optional module and interconnected to its neighboring markets via the available transmission capacities. In recent years in Europe, market coupling has made steady progress and, in 2015, a flow-based approach was introduced (EPEX SPOT, 2016), replacing the ATC-based approach used before (European Energy Exchange [EEX], 2011). As cross-border effects are strongly influenced by the way market coupling is implemented, an algorithm was chosen that resembles the actual market design and can be divided into the following steps:

First, in each area, agents are called upon by a national market opera- 
Market $A$

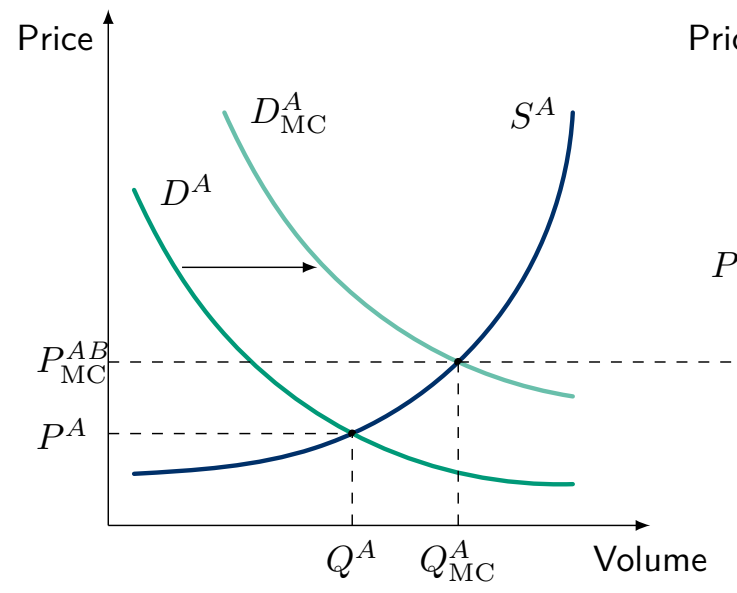

Market $B$

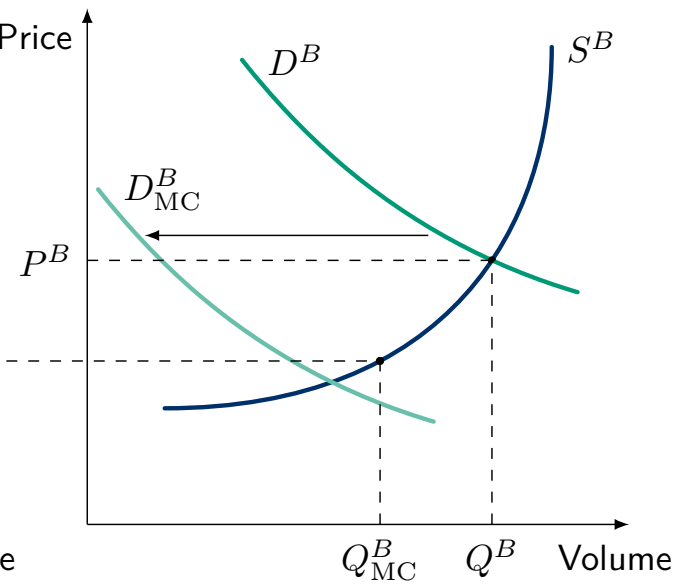

Figure 2: As sufficient transmission capacity between the two interconnected markets is available, prices converge to $P_{\mathrm{MC}}^{A B}$ and the economic welfare increases. However, this does not imply that each market participant is better off. For example, consumers in market $A$ have to pay a higher price than they would pay without market coupling.

tor to submit bids for the day-ahead market for each hour of the following day. The bids are based on the variable costs of the generation capacity units but can also include a markup in scarcity hours (Keles et al., 2016a). Next, all national bids are submitted to a central operator that applies a welfare-maximizing market clearing algorithm subject to the available interconnection capacity as well as the balance of supply and demand in each market area 1$]$ As shown in Figures 3 and 2, the algorithm leads to a convergence of market prices and, in the case of sufficiently large transmission capacities, identical prices.

\footnotetext{
${ }^{1}$ For further details, for example, the mathematical formulation of the market clearing problem, refer to Ringler et al. (2017).
} 


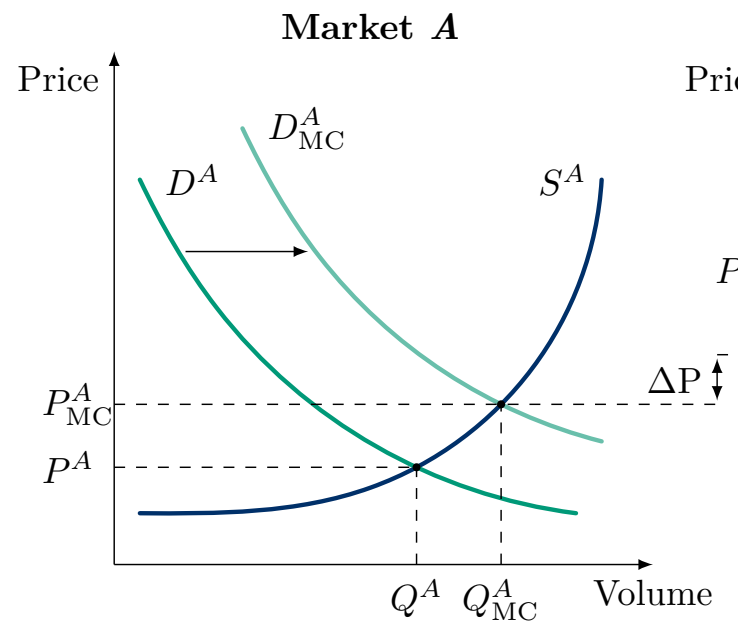

Market $B$

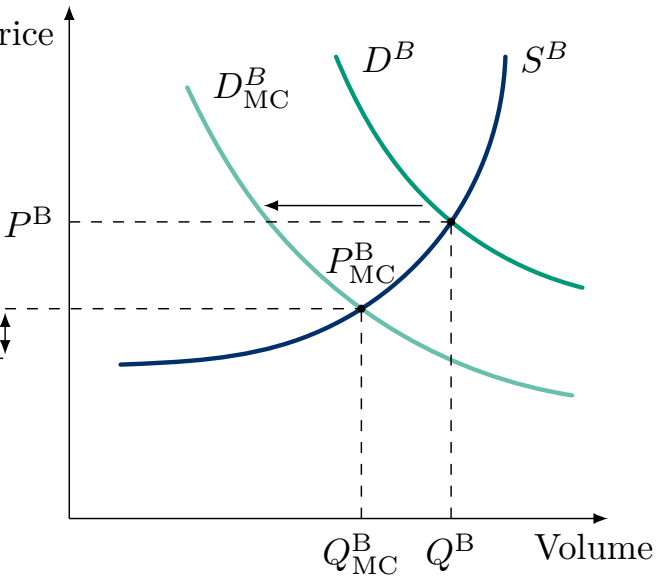

Figure 3: As there is lower-cost generation capacity available in Market $A$, Market $B$ imports electricity. Thereby, a smaller part of its local demand $D_{M C}^{B}$ has to be covered by its own supply $S^{B}$ and the price in market $B$ decreases. In market $A$, the situation is exactly the opposite. Generation capacities from market $A$ serve an overall higher demand $D_{M C}^{A}$, thus more expensive capacities are required, and the price in market $A$ rises. However, as only insufficient transmission capacity is available, no uniform price is reached, but a price difference of $\Delta P$ remains.

\subsection{Capacity expansion}

The model contains an investment planning module, which is executed once a year within the chosen time horizon. Thereby, different investment options of flexible power plants are compared according to a certain economic criterion, e.g., the net present value. Potential revenues for power plants can be generated from selling electricity in energy spot markets as well as from participating in different CRMs (e.g., central capacity market, SR) depending on the respective market area configuration. Investment agents in all market areas evaluate different power plant options. Data and assumptions on which the prediction is based are future electricity demand as well as fuel and emission price developments in the following years (see Section 4.1). Based on these data, a price forecast is firstly made for future prices in the respective 
market areas. Each agent $a$ from all market areas calculates the NPV for each available investment option $j$ according to Equation 1 .

$$
\mathrm{NPV}_{j, a}=-I_{0, j}+\sum_{t=1}^{n_{j}} \frac{-c_{t, j}^{\mathrm{fix}}+\sum_{h=1}^{8760} \max \left\{p_{h, t, a}^{\mathrm{prog}}-c_{h, t, j}^{\mathrm{var}}, 0\right\}}{(1+i)^{t}} \quad \forall j, a
$$

Calculation of the NPV is based on the investment payment $I_{0}$, the economic lifetime $n$, interest rate $i$, fixed $\operatorname{costs} c^{\text {fix }}$ price forecast $p^{\text {prog }}$ and variable costs $c^{\mathrm{var}}$.

Investment options are predetermined exogenously based on the scenario (Table 2) and represent a specific flexible power plant type, such as a gas turbine. The options include all economic (e.g., investment $I_{0}$ or investment horizon $n$ ) and technological parameters (e.g., efficiency, net capacity) that vary over the simulation period. In addition, future technological developments such as carbon capture systems are taken into account in various investment options.

For calculation of the expected annual revenues of the spot market, an hourly electricity price forecast $p^{\text {prog }}$ is used. The price forecast for the calculations works analogously to the determination of the spot market price by applying a welfare maximizing market coupling. The variable costs $c^{\text {var }}$ for each hour $h$ of the year $t$ are deducted from $p^{\text {prog }}$. As a power plant only produces if at least the variable costs are covered, all negative cash flows are excluded (neglecting must-run conditions, start-up costs, and minimum downtimes). For calculation of the variable costs, fuel prices, and carbon certificate prices are assumed to be the same in all market areas. 
A list with the NPV values of all power plant options is created for all agents $A$ from all market areas. From this, the option $j^{*}$ is selected that reaches the highest positive $\mathrm{NPV}^{*}$ (according to Equation 2) of all agents.

$$
j^{*}=\max \mathrm{NPV}_{j, a} \quad, \forall j: \mathrm{NPV}_{j}>0 \quad \& \quad a \in A
$$

Each investment increases the totally installed capacity and thus influences prices. Consequently, no investor would make an investment with an initial positive NPV, if it affects prices to such an extent that the own new investment becomes unprofitable. Therefore, a new price forecast is calculated after each investment decision for option $j^{*}$. Subsequently, $j^{*}$ is revaluated with the new price forecast. If the $\mathrm{NPV}^{*}$ of $j^{*}$ is still positive, the agent invests in option $j^{*}$. If the $\mathrm{NPV}^{*}$ of $j^{*}$ is not positive, a new price forecast is calculated with the option with the second highest NPV and so on until an investment is made. If no investment with a positive NPV is available, the algorithm terminates, and no further investments are made in the simulation year. The investment process is repeated every year of the model horizon.

\subsection{Modeling capacity remuneration mechanisms}

In recent years, some countries have introduced CRMs, thus making it necessary to extend the PowerACE model with this very feature. PowerACE is able to consider SR and other types of CRMs (Keles et al., 2016a; Bublitz et al., 2015). For this analysis, only the SR for Belgium and Germany as well as a decentralized capacity market for France and a central capacity market for Italy are applied (see Figure 4). The payments of the modeled mechanisms are also taken into account for the NPV calculation described 


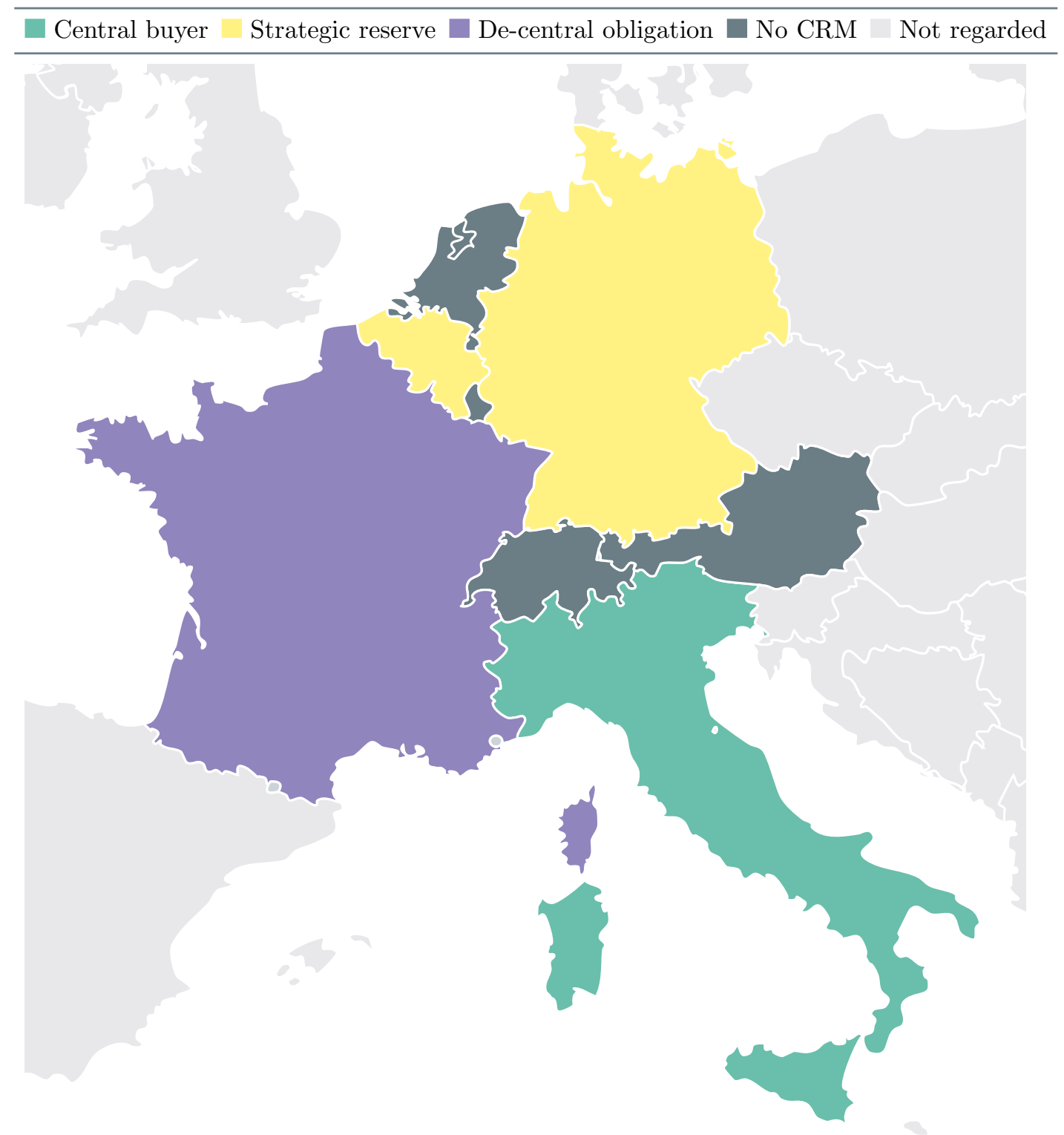

Figure 4: In the model, the following countries are included with the already implemented and planned CRMs: Austria, Belgium, France, Germany, Italy, Luxembourg, the Netherlands, and Switzerland. 
in Section 3.3 .

Strategic reserve

Every year, the national transmission system operators in Belgium and Germany organize an auction to procure the necessary capacity for the SR. In order to participate, a generation unit must be available within a certain time, i.e., after a cold start time of less than 10 hours. The selection of generation capacity is determined by the submitted capacity price without considering electricity generation costs. Generators offer their capacities based on their respective annual fixed and opportunity costs. The opportunity costs correspond to the expected lost profits from the other markets, as contracted entities are prohibited from participating in other markets. This restriction remains in effect even after expiry of the contract term, and hence obeys the no-way-back rule. Once a power plant is part of the SR, its operational control is carried out by the transmission system operator. The reserve is used only in extreme situations when no balance between supply and demand can be achieved. In this case, the operator offers the reserve in the day-ahead market at the maximum allowed price. The generation units are activated in the order of their variable costs: First, the unit with the lowest variable costs is dispatched, then the more expensive ones. The owner receives a recompensation for the costs additionally incurred during the operation time (e.g., fuel and carbon costs). For further details regarding the implementation of the SR refer to Bublitz et al. (2015). 


\section{Capacity markets}

France The implementation of the French capacity market (RTE, 2017), which was particularly developed for this investigation, is described in detail in Zimmermann et al. (2017) or Kraft (2017). Firstly, the reference capacity demand (based on the future annual peak demand) including an exogenously defined security factor is calculated. Depending on the reference capacity, the capacity obligations of the obligated parties (i.e., supply companies and large consumers) are specified depending on their shares in total peak demand, so that each obligated party has to cover the amount of its own demand.

Secondly, the supply price of the generation capacities is determined due to the expected income on the electricity market for each generation unit based on the yearly difference costs. Difference costs are defined as the gap between the yearly income on the energy market and the required income to break even a generation unit's profitability. Finally, annual payments are derived due to the capacity obligations and the difference costs of the supply units.

Italy The central capacity market with capacity options, applied, e.g., in Italy, is based on the Forward Capacity Market, which is currently implemented in the market area of the US system operator ISO New England (2014), and is adjusted to the Italian market area, which is outlined in Keles et al. (2016a). In the model, with a lead time of four years, the regulator agent determines the conventional capacity requirement which is calculated based on the forecasted peak load in the respective year of execution minus the contribution of RES to the generation adequacy (on the basis of 
predefined capacity credits). The regulator, as the central agent, buys the whole capacity for the market area in the model including all reserve margins based on a certain demand curve (Cramton and Stoft, 2005). Afterwards, the generation units receive this payment.

\subsection{Output}

One of the main outputs of the model within this article are the hourly spot electricity prices for each market area. These electricity prices reflect both the national situation (e.g., market design, demand, and generation mix) as well as developments in interconnected markets (e.g., welfare effects, cross-border flows). Therefore, determining the profitability of existing and new generation units is also a result of this study. Given the possibility of varying model parameters (e.g., with certain CRM activated) and input data (e.g., fuel and carbon prices varied), the agent-based simulation model PowerACE is suitable to analyze a range of different scenarios. Several investigations have been conducted by the authors in the past (e.g., Keles et al., 2016b) using the PowerACE modeling approach. In order to analyze cross-border effects, the PowerACE model has been improved with regard to the methodology and the spatial resolution. The methodological extensions are inter alia the implementation of the French capacity market as well as the hydropower dispatch module (Appendix A), in particular for Austria and Switzerland. Furthermore, the long-term price forecast, which is used in particular in the investment planning module, as well as the investment planning module itself have been improved regarding the consideration of

market coupling effects. Geographical extensions include the market areas of Switzerland, Italy, and Austria, whereas, before the extension, the model was 
limited to the Central Western European (CWE) market area. (See Ringler et al., 2017; Keles et al., 2016a)

\section{Case study: Switzerland}

\subsection{Input data}

In this section, a scenario framework will be defined in accordance with the modeling approach (Section 3). Therefore, assumptions are made for the development of electricity demand, fuel and carbon certificate prices, and the costs of generation technologies.

This requires the selection and processing of large amounts of data (Table 11) to be used in the scenario runs (Table 2). The EU Reference Scenario (European Commission, 2016) was used to derive fuel and carbon prices. All of the flexible fossil power plants in the modeled areas are based on the $\mathrm{S} \& \mathrm{P}$ Global Platts (2016) power plant database. Regarding the market coupling, the trading capacities between the market areas are derived from NEP (2018) and ENTSO-E (2018a). Investments in new flexible power plants as well as assumptions of fixed and additional variable costs (in addition to the costs of fuel and carbon certificates) for the power plants are based on Schröder et al. (2013). Due to the high resolution of the model, hourly RES feed-in and electricity demand profiles (year 2015) are used as initial data taken from ENTSO-E (2018b) and Swissgrid (2015). The yearly development of the demand and the RES feed-in volume is taken from European Commission (2016) for the EU countries and from Prognos AG (2012) (Scenario C\&E) for Switzerland. All profiles are scaled according to the underlying development in the modeled years. Hydropower plants play a crucial role in the Swiss 
Table 1: In this table, an overview is provided over the main data used in all scenarios.

\begin{tabular}{|c|c|c|}
\hline Input data type & Resolution & Other countries \\
\hline $\begin{array}{l}\text { Conventional } \\
\text { power plants }\end{array}$ & Plant/unit level & $\begin{array}{c}\text { Based on S\&P Global Platts (2016), } \\
\text { extended with own assumptions }\end{array}$ \\
\hline $\begin{array}{l}\text { Fuel and carbon } \\
\text { prices }\end{array}$ & Yearly & European Commission 2016 ) \\
\hline $\begin{array}{l}\text { Investment } \\
\text { options }\end{array}$ & Yearly & Schröder et al. $(2013)$ \\
\hline $\begin{array}{l}\text { Transmission } \\
\text { capacity }\end{array}$ & Yearly & ENTSO-E (2018a), NEP (2018) \\
\hline $\begin{array}{l}\text { Electricity } \\
\text { demand and } \\
\text { RES feed-in }\end{array}$ & $\begin{array}{l}\text { Hourly } \\
\text { aggregated per } \\
\text { market area }\end{array}$ & 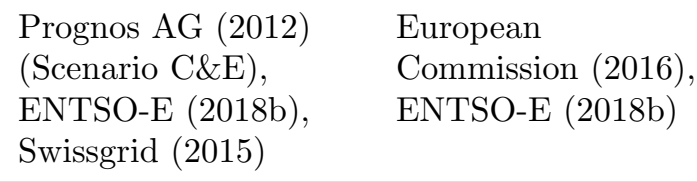 \\
\hline
\end{tabular}

electricity market. The aggregated capacities of hydro river, seasonal hydro storage, and pumped storage power plants kept constant at $16.6 \mathrm{GW}$ in total and are taken from Swiss Federal Office of Energy (2018d).

In order to examine the effects of the CRMs in detail, various scenarios and sensitivities are calculated using the agent-based model for a time horizon from 2015 to 2050 to evaluate the individual market designs for the simulated market areas. These are shown in Table 2,

\subsection{Price development}

The EOM scenario is characterized by the fact that only EOMs are implemented in all of the modeled markets. This means that all income from flexible power plants is generated by the sale of electrical energy on the wholesale electricity market. The CRM Policies scenario describes the currently implemented and decided market designs in the modeled market areas/countries. It is a close-to-reality representation of the circumstances prevailing at the time this investigation was being processed. 
Table 2: The applied market designs for the different scenarios for each country are described. Whereas CRM Policies represents a scenario with currently implemented policies, the counterfactual EOM scenario and DE Strategic sensitivity are used to analyze the effects of CRMs. // EOM = Energy-only market, $\mathrm{SR}=$ Strategic reserve, $\mathrm{DCM}=$ Decentralized capacity market, $\mathrm{CB}=$ Central buyer.

\begin{tabular}{lclc}
\hline & CRM Policies & EOM & DE Strategic reserve sensitivity \\
\hline Austria & EOM & EOM & EOM \\
Belgium & SR & EOM & SR \\
France & DCM & EOM & DCM \\
Germany & SR $5 \mathrm{GW})$ & EOM & SR $(2 \mathrm{GW})$ \\
Italy & CB & EOM & CB \\
Netherlands & EOM & EOM & EOM \\
Switzerland & EOM & EOM & EOM \\
\hline
\end{tabular}

\subsubsection{Price validation}

To verify the results, a short validation based on historical prices is carried out in advance. Table 3 shows the comparison of real electricity wholesale prices, of the years 2015 and 2016 (EPEX SPOT, 2018a), and the prices that are calculated in the PowerACE simulation. In some cases, there are larger deviations. Concerning the German price deviation, it has to be mentioned that several market areas around Germany (e.g., Denmark, Poland) have not yet explicitly been modeled in PowerACE. Although the exchange flows with these markets are considered via static exchange, only the hourly volume effects, but not price effects of these flows are taken into account. Calculations with all neighboring market areas of Germany in PowerACE show that the mean value of deviations was below 2 EUR/MWh for Germany and Austria in the years 2015 and 2016. Furthermore, the carbon certificate prices in this study are derived from the EU Reference Scenario (European Commission, 2016), but in reality, the carbon certificate prices were lower in these years, which also explains some of the higher electricity prices in the simulation. 
The error between simulated and historical series is quite small for the Swiss and French electricity prices. In general, the price validation delivers sufficiently good results except for Italy. The main reason for the deviation in Italy is that there is no internal splitting of Italy into different price zones in the model as it is the case in reality. Therefore, no domestic grid restrictions in Italy are taken into account that would shorten the market in the different zones and lead to higher prices in the model. Higher prices in the different zones in Italy lead to a higher average than in the case of considering Italy as an unique market zone.

Table 3: Price validation of the PowerACE model: Comparing day-ahead wholesale historical and simulated prices. Simulated prices are similar in both scenarios for 2015 and 2016 and stated in EUR/MWh. Source: EPEX SPOT (2018a)

\begin{tabular}{|c|c|c|c|c|}
\hline \multirow[t]{2}{*}{ [EUR/MWh] } & \multicolumn{2}{|c|}{2015} & \multicolumn{2}{|c|}{2016} \\
\hline & hist. & sim. & hist. & sim. \\
\hline Switzerland & 40.30 & 43.41 & 37.88 & 38.29 \\
\hline Germany/Austria & 31.63 & 43.51 & 28.98 & 38.48 \\
\hline France & 38.48 & 39.07 & 36.75 & 34.17 \\
\hline Italy-North* & 52.71 & 42.64 & 42.67 & 38.01 \\
\hline
\end{tabular}

${ }^{*}$ The national average price (PUN) in Italy was $52.31 \mathrm{EUR} / \mathrm{MWh}$ in 2015 and 42.78 EUR/MWh in 2016.

\subsubsection{Wholesale prices in the scenarios}

Looking at the simulated wholesale prices in the EOM (Figure 5) and in the CRM Policies scenario (Figure 6), it is immediately visible that the prices in France are clearly below the prices for all other market areas until approximately 2035. The reason for this is the high proportion of nuclear power plants in France, which are not affected by rising carbon certificate prices and set the prices at a lower level in France due to their low marginal costs. Due to the limited trading capacities between the countries, the other mar- 
ket areas can only partly profit from these low prices. Moreover, the priceincreasing effects of exchange trades with Spain and Great Britain (which are connected to the French grid and tend to have a higher price level) are missing in the model due to the chosen system boundaries. This leads to large deviations between the French prices and the other market prices until trading capacities between the modeled countries are substantially increased. In addition, few new nuclear power plants are built in France during the time horizon of the analysis (only towards the end of the simulation period), but rather gas-fired power plants, which in terms of prices align with the other market areas. This can be observed in both scenarios. Therefore, from 2035 onwards, prices in the EOM scenario rise significantly due to scarcity prices within several hours caused by less installed capacity and increasing carbon certificate prices. The average prices in the model in the years 2041 and 2043 are thus over $120 \mathrm{EUR} / \mathrm{MWh}$ in the EOM scenario. In the following years, however, the average price is observed to fall again, because these prices again incentivize new investments.

In all modeled market areas, prices are developing in a similar way. Only Italy has average prices slightly below the other areas considered from 2035 onwards. These differences are due to the still limited exchange capacities to neighboring countries together with high RES production in Italy, so that it is no longer possible to export more electricity in the corresponding hours. E.g., in the year 2043, Italy on the average generates $39 \mathrm{GW}$ from RES in the hours with fully used export capacities. This RES production lowers the average wholesale price. From 2035, the picture is similar for the CRM Policies scenario as in the EOM scenario, with the difference that the average 


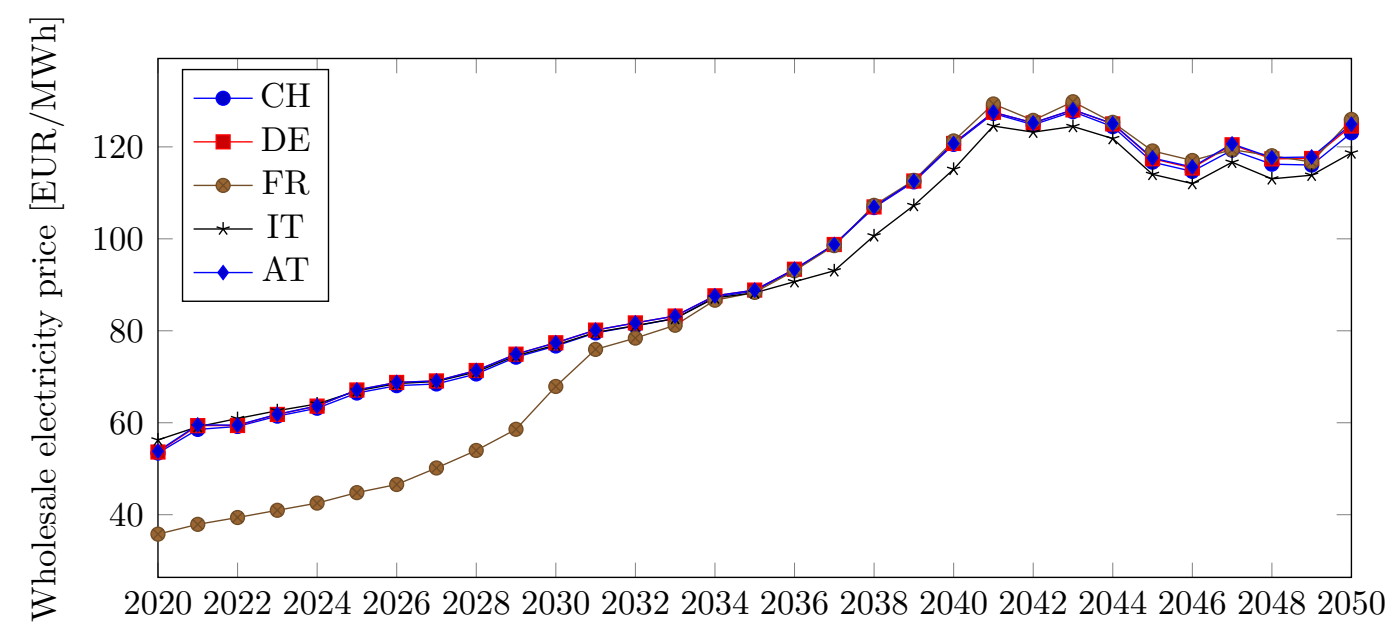

Figure 5: The simulated wholesale prices in the EOM scenario show a strong increase. With the decommissioning of nuclear power plants, French prices rise to a similar level as in other market areas.

prices are significantly lower. The absolute price deviations of the wholesale market prices of the different scenarios are at the beginning (until 2023) only caused by the introduction of the SR in Germany because the power plants will be taken out of the market. Until 2035, the prices of both scenarios are almost the same, the EOM average prices are even slightly below the average prices of the CRM Policies scenarios. From 2035 onwards, however, prices deviate significantly due to the occurrence of scarcity caused by an insufficient supply in various market areas in the EOM scenario (Figure 7). The prices remain lower (see Figure 6) due to sufficient capacities in the CRM Policies scenario.

For Switzerland, this deviation of the average prices is shown in Figure 7. The maximum difference between the yearly average prices of the EOM scenario and the CRM Policies scenario is more than 27 EUR/MWh in some years after 2035. This high price difference is, of course, due to the higher 


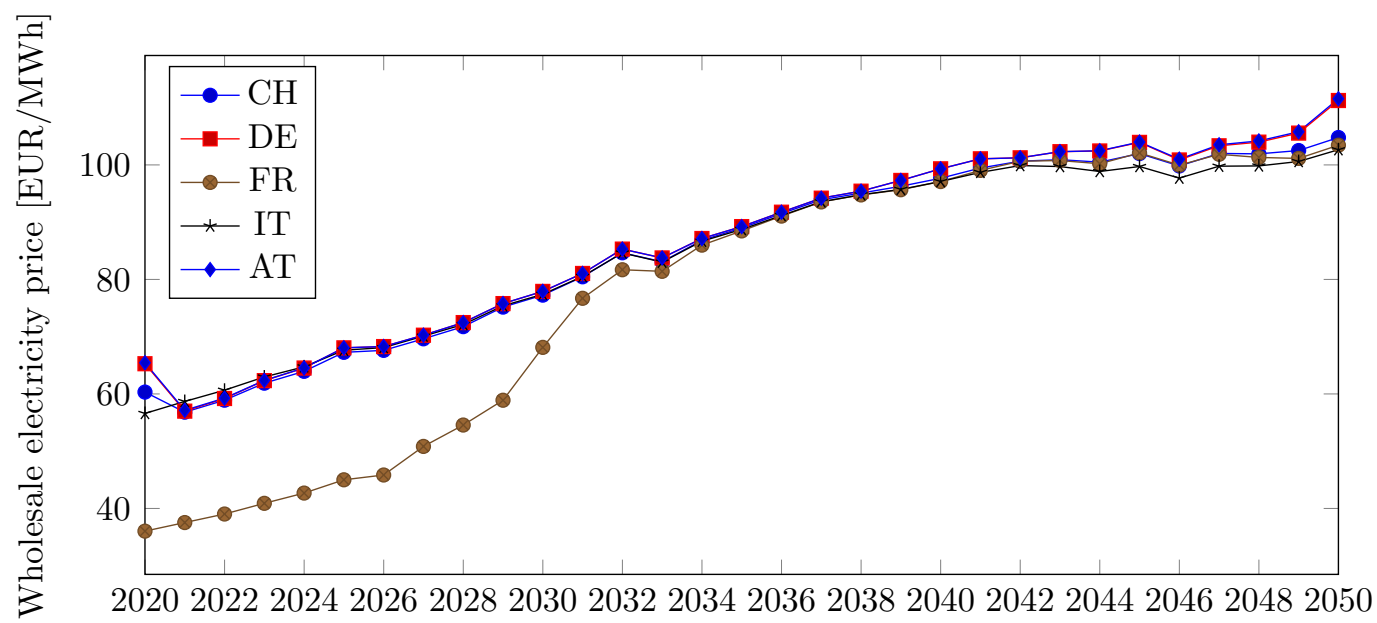

Figure 6: The simulated prices in the CRM Policies scenario also show a strong increase, although the overall level is lower than in the EOM scenario.

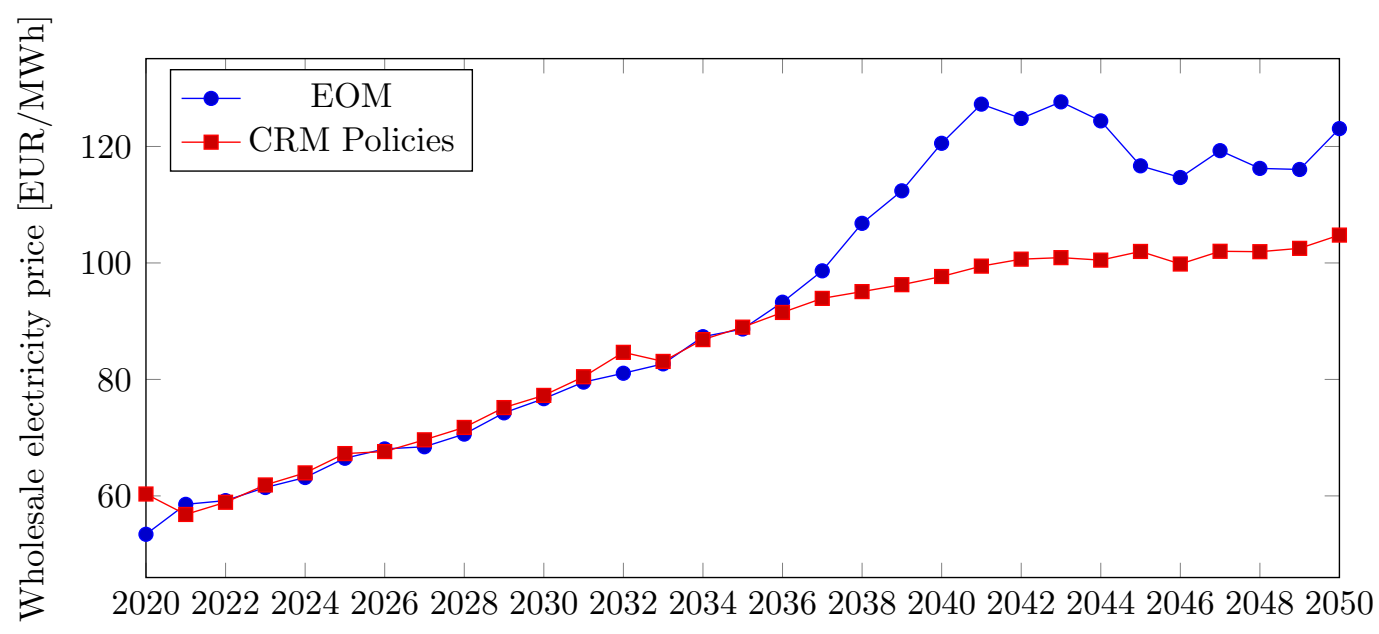

Figure 7: In the long term, the simulated prices for the CRM Policies scenario are lower than in the EOM scenario as Swiss consumers benefit from increased abroad generation capacities.

flexible capacities in France and Italy, which are available at any time. The neighboring countries also profit from the high installed capacity that is signaled by fewer hours in which the market cannot be cleared (Table 5). 
Regarding the prices and the capacity development, the picture is ambivalent for Switzerland. On the one hand, less will be invested in the CRM Policies scenario, prices are lower than in the EOM scenario(see Section 4.3), and Swiss hydropower offers enough capacity at all hours to ensure that the wholesale market can always be cleared (see Section 4.4). However, on the other hand, compared to the neighboring countries, the EOM scenario does not have many hours in which the market does not provide sufficient supply, but at significantly higher prices. However, CRMs also causes costs (and could lead to inefficient investments), but this is not relevant to Switzerland because these costs for CRMs are normally allocated within the CRM implementing countries.

\subsection{Generation capacities}

\subsubsection{EOM scenario}

In the EOM scenario, the total installed conventional capacity across all countries decreases, with the exception of Austria. This can be explained by overcapacities, especially in Germany, and by better counterbalancing effects across the various market areas. For instance, market coupling and expansion of trading capacities allow larger volumes of energy exchanges across countries. However, there is a short-term increase in capacity in 2030 and 2035 in the model runs (Table 8). This can essentially be explained by the closure of large nuclear capacities in France, so that with a (purely hypothetical) assumption of the maximum operating life of nuclear power plants being 50 years, starting in 2027, their total capacity shrinks from over $60 \mathrm{GW}$ to less than $10 \mathrm{GW}$ within 15 years (excluding new investments) (Zimmermann et al. 2017). This leads to raised prices in the forecast module 
in consecutive years and in some cases to anticipated investments in new power plants. However, after 2035, the capacity falls back below the level of before 2030 both in France and in all countries considered. After 2035, the reason for the reduction of the installed conventional capacities is the growth of RES in all countries.

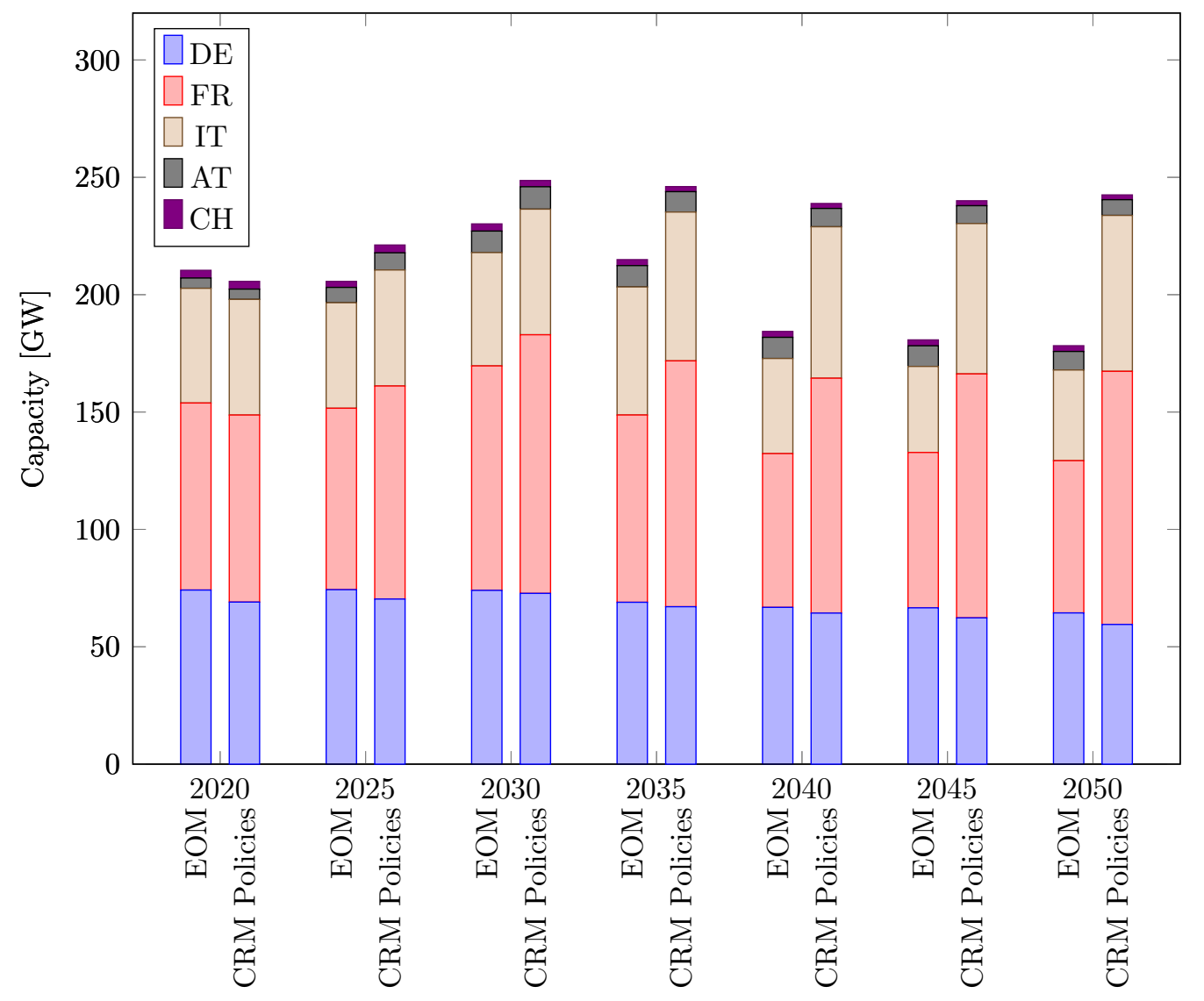

Figure 8: The main differences between the EOM and in the CRM Policies scenario can be seen in France and Italy. There, the introduction of capacity markets leads to higher capacities from 2025 onwards and to a more constant conventional capacity development than in the EOM scenario. 
Table 4: Investments in Switzerland in new flexible power plants in the the different scenarios in $[\mathrm{MW}]$.

\begin{tabular}{ccccc}
\hline$[\mathrm{MW}]$ & \multicolumn{2}{c}{ Gas Combined Cycle } & \multicolumn{2}{c}{ Open Cycle Gas Turbine } \\
Year & EOM & CRM Policies & EOM & CRM Policies \\
\hline $2020-2024$ & - & - & - & 800 \\
$2025-2029$ & 1200 & - & - & - \\
$2030-2034$ & 800 & 1200 & - & - \\
$2035-2039$ & 400 & - & - & - \\
\hline
\end{tabular}

However, Austria is an exception, because of the newly introduced market splitting between Austria and Germany (since October 2018) and the merely static exchange with the Czech Republic, Hungary, and Slovenia without price effects. The latter issue could distort prices to such an extent that investments in Austria appear profitable in the model because of high price forecasts due to low installed capacity. For better illustration, Figure 8 shows the conventional capacity development without RES while Figure B.15 (in the Appendix) depicts capacity development with dedicated RES development.

Figure 9 shows capacity development in Switzerland, including all RES capacities, broken down by the respective generation technologies. While the nuclear power plants will be completely phased out by 2035 due to the assumed maximum lifetime of 50 years, the capacity will be replaced by new investments in combined cycle gas turbines (CCGTs) (Table 4) up to a total capacity of $2.4 \mathrm{GW}$. However, if the nuclear power plants are operated for a longer period, this picture may change.

The increase in installed RES capacity in Switzerland is mainly caused by the growth in solar power plants, due to the input data. The installed wind capacity increases from $367 \mathrm{MW}$ in 2020 to $2367 \mathrm{MW}$ in 2050 and for 


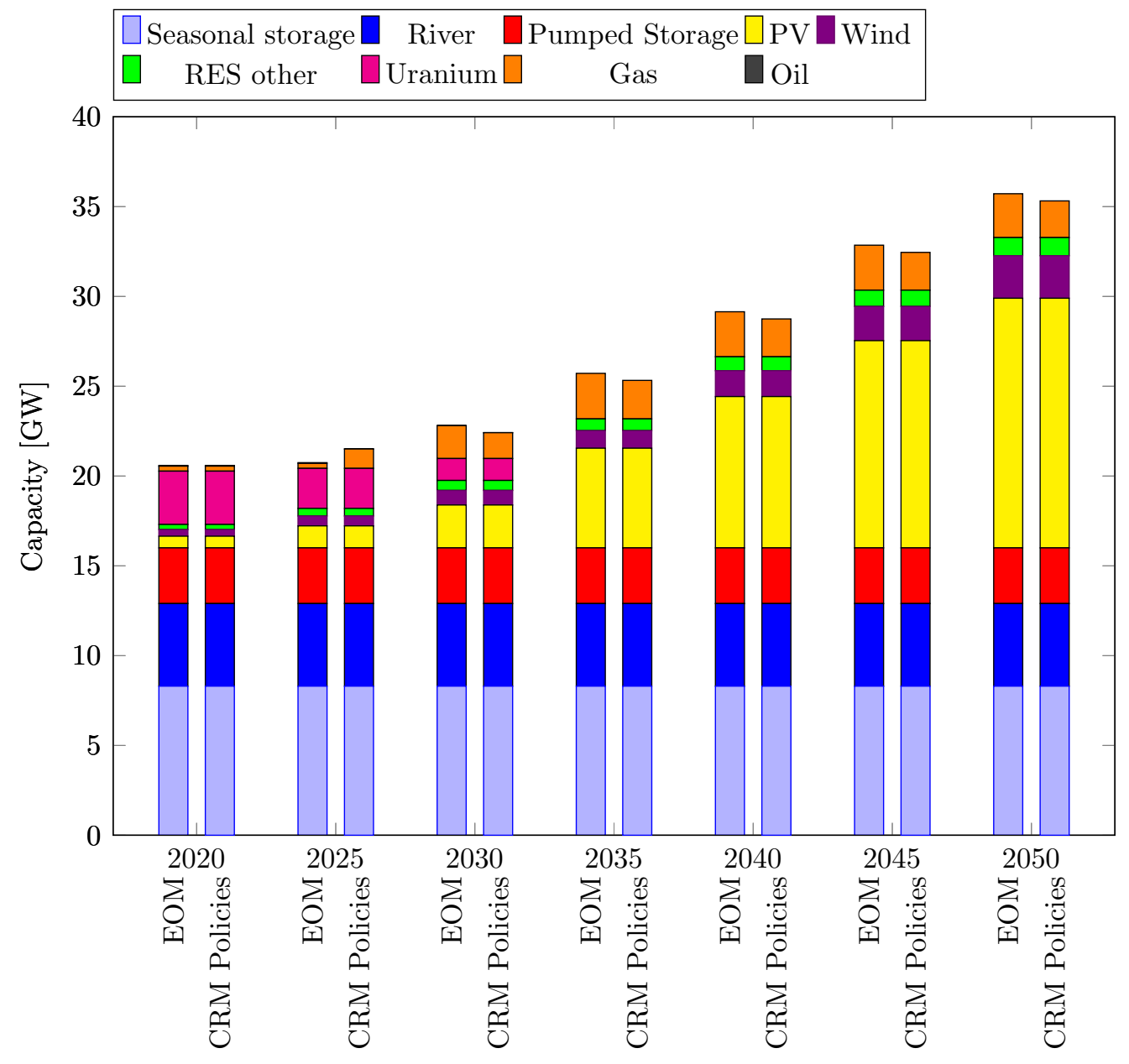

Figure 9: Due to the complete decommissioning of nuclear power plants, the capacities are being replaced by new investments in gas-fired combined cycle power plants and the expansion of renewable energies, especially photovoltaics.

solar from $650 \mathrm{MW}$ in 2020 to $13900 \mathrm{MW}$ in 2050. As a result, the total generation capacity rises from over $21 \mathrm{GW}$ in 2020 to over $36 \mathrm{GW}$ in 2050 in the EOM scenario. 


\subsubsection{CRM Policies scenario}

For the study of CRM market designs, availability factors of $6 \%$ for wind and $1 \%$ for PV were assumed at all hours. In particular in Italy, conventional power plants are considered with a $90 \%$ availability in the CRM and for the capacity market auction, an additional reserve of $3 \%$ of the peak load is implemented. For France, a security factor of 1.03 as well as capacity credits for wind $(20 \%)$ and solar $(5 \%)$ defined by RTE (2017), are applied for the first years. For Germany, the SR ('Kapazitätsreserve') allocates 5 GW. In all market areas, DSM (interruptible load) capacities in the amount of $2 \%$ of the maximal peak load for a price of $700 \mathrm{EUR} / \mathrm{MWh}$ are assumed.

In the CRM Policies scenario, all model results are generated considering already implemented or proposed CRMs. Therefore, the introduction of the capacity markets in France and Italy leads to significantly higher capacities and to a more constant conventional capacity development in these countries compared to the EOM scenario (see Figure 8). In the scenario with CRMs, the increasing demand for flexible generation capacity is driven by the peak demand plus potential security margins, e.g., defined by the regulatory authority.

RES can have a mitigating effect on the rise of the conventional capacity demand caused by the CRMs. However, due to the fluctuating behavior of RES, they may only participate to a certain extent in the capacity market (or by reducing peak residual demand). This also depends on the respective design or parameterization of the CRMs. However, as a result of the capacity credits, the sum of the required and installed conventional capacity corresponds to almost peak demand in the overall market area due to the 
CRM configuration.

For illustration, Figure 8 shows the capacity development in Switzerland and the neighboring countries while Figure B.15 (in the Appendix) depicts the development together with the RES capacities. In Table 4 , the investments in new power plants are listed. Investments are made purely in gas-fired power plants $(2 \mathrm{GW})$ in the CRM Policies scenario. However, investments not only in CCGTs, but also in open-cycle gas turbines (OCGTs) are part of the results. The OCGTs outperform CCGTs in terms of capital costs. Therefore, the agents choose the OCGTs if the power plant is mainly built to provide reserve or if the power plant is dispatched only for a small number of hours in the spot market with low average market prices. Figure 9 shows the total development of Swiss capacities, i.e., including RES. As a result, the total capacity will rise from over $21 \mathrm{GW}$ (in 2020) to almost $36 \mathrm{GW}$ in 2050.

\subsection{Generation adequacy}

The generation adequacy is illustrated here in the form of hours and expected volumes where the electricity spot market cannot be cleared normally. Table 5 summarizes and aggregates the number of hours in which the spot market in the PowerACE model cannot generate a feasible market result with usual generation capacities. Hence, either immediately-switchable capacity is necessary for market clearing (DSM) or the market cannot be cleared due to insufficient supply ("No market clearing, therefore price is $3000 \mathrm{EUR} / \mathrm{MWh}$ (EPEX SPOT, 2018a)). However, this does not necessarily indicate blackor brownouts, because there is, for instance, still the available control reserve capacity. The availability of DSM potential is assumed to be $2 \%$ of the peak 
Table 5: Cumulated hours with the use of DSM or no market clearing in the simulated time horizon from 2020 to 2050 in the EOM scenario.

\begin{tabular}{llrrrrr}
\hline & Unit & CH & DE & FR & IT & AT \\
\hline EOM scenario & & & & & & \\
DSM usage & {$[\mathrm{h}]$} & 846 & 988 & 982 & 725 & 834 \\
No market clearing & {$[\mathrm{h}]$} & 0 & 492 & 541 & 308 & 2 \\
Expected load not served & {$[\mathrm{MW}]$} & 0 & 5337 & 5470 & 3992 & 1127 \\
CRM Policies scenario & & & & & & \\
DSM usage & {$[\mathrm{h}]$} & 14 & 165 & 0 & 0 & 88 \\
No market clearing & {$[\mathrm{h}]$} & 0 & 42 & 0 & 0 & 17 \\
Expected load not served & {$[\mathrm{MW}]$} & 0 & 1936 & 0 & 0 & 1042 \\
\hline
\end{tabular}

demand in all market areas. Table 5 indicates the accumulated number of hours with the use of DSM or with no market clearing for both scenarios. Furthermore, the expected energy not covered in the case of a non-feasible market result in the spot market is specified in the same table.

In Switzerland, the lower installed generation capacity in the CRM Policies scenario does not increase the number of hours in which the market cannot be cleared or the hours when DSM is needed to clear the market successfully. On the contrary, the number of hours with DSM dispatch even falls due to higher flexible capacity in the neighboring countries compared to the EOM scenario. In the EOM scenario, the market can be cleared at all hours, which is caused by the use of DSM and the high hydropower capacity. In the CRM Policies scenario, only Austria has many hours in which the market cannot be cleared.

Figure 9 shows the flexible capacities in Switzerland in the two scenarios. Due to the slightly lower market prices and the higher flexible capacities (stimulated by CRM) in the neighboring countries France and Italy, the total installed capacity in Switzerland is lower (by 400 MW from 2030) in the CRM 
Policies scenario. However, this does not increase the number of hours, in which the market cannot be cleared, or the hours when DSM is needed to successfully clear the market, as more capacities from the neighboring market areas are available also for the Swiss market.

\subsection{Sensitivity analysis for the size of the strategic reserve in Germany}

In order to consider other possible developments, an additional scenario is added and the results are briefly presented in this chapter. In this scenario, the strategic reserve in Germany is reduced to $2 \mathrm{GW}$ (instead of $5 \mathrm{GW}$ ), as the current regulation allocates a maximum of $2 \mathrm{GW}$ until 2025, however, maximal $5 \mathrm{GW}$ are legally permissible.

In the scenario, there is hardly any difference in the development of prices (Figure 10) and capacities (Figure 11) in Switzerland. It is necessary to compare the results of the model simulations with $2 \mathrm{GW}$ SR in Germany (DE strategic reserve sensitivity) with those of the CRM Policies scenario, as no $\mathrm{SR}$ is used in the pure EOM scenario and the results would be, therefore, identical.

With regard to the prices shown in Figure 10, only marginal differences are identifiable. In the years 2020 to 2022 in particular, a deviation in the prices is discernible, as the SR in Germany starts in 2020 and capacities are taken out of the market. Moreover, some years later (around 2044), there will be further slight differences in annual average wholesale prices. However, lower than 2.50 EUR/MWh. 


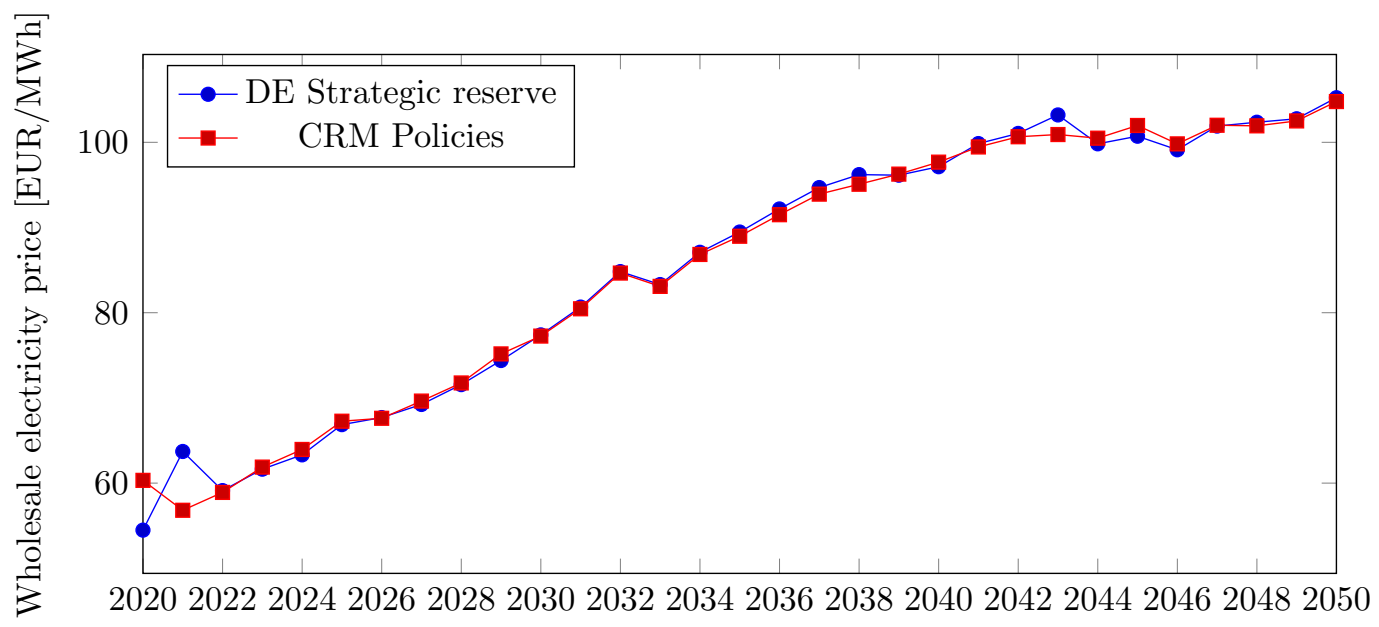

Figure 10: Development of the simulated market clearing wholesale prices in Switzerland for the CRM Policies scenario and with the reduced SR of $2 \mathrm{GW}$, which is currently proposed until 2025.

These minor differences in prices do not affect capacities and incentivize investments in the scenario. This becomes clear in Figure 11. At the beginning, compared to the CRM Policies scenario higher capacity in Germany, this does not lower the capacity in Switzerland, since rather old power plants are allocated to the SR, and old power plants leave the market sooner. 


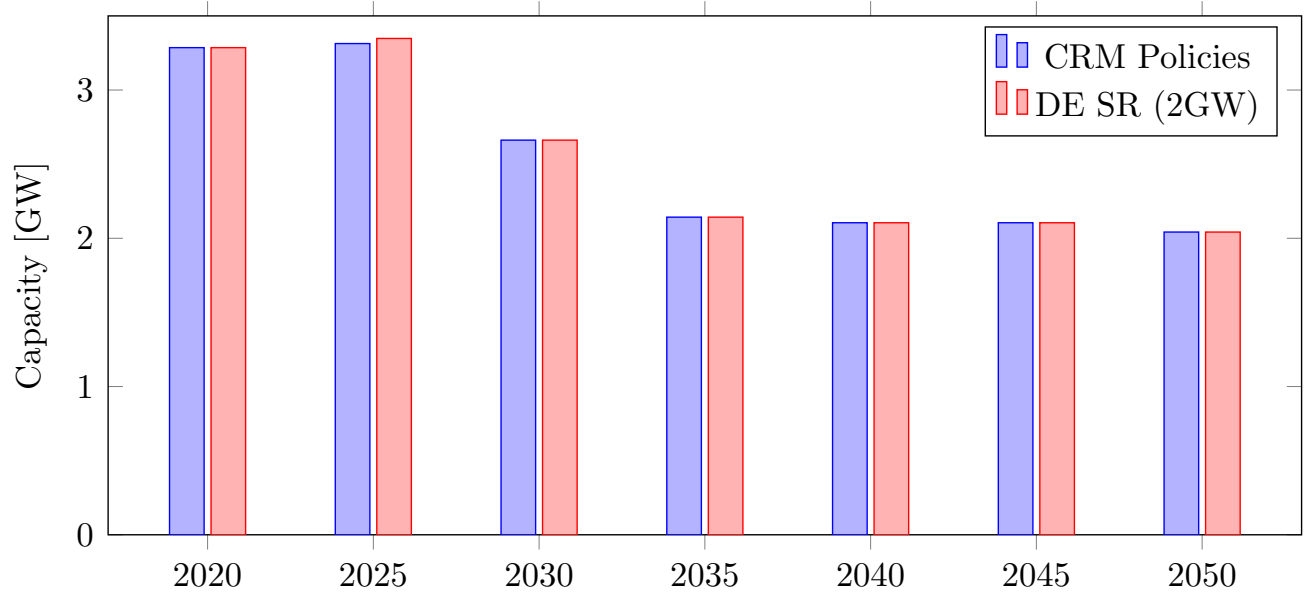

Figure 11: Capacity development in Switzerland in the DE Strategic reserve sensitivity scenario and the CRM Policies scenario.

In 2021, the increase in prices in the DE Strategic reserve sensitivity scenario is caused by the fact that in the scenario with $5 \mathrm{GW}$ SR (CRM Policies), investments are made promptly due to the higher capacity taken out of the market and thus the market price falls. In the DE Strategic reserve scenario, initially no investments are made, but therefore shortages occur in the market and the prices rise.

Table 6: Cumulated hours with the use of DSM or no market clearing in the simulated time horizon from 2020 to 2050 in the DE Strategic reserve sensitivity scenario with a SR of $2 \mathrm{GW}$.

\begin{tabular}{llrrrrr}
\hline & Unit & CH & DE & FR & IT & AT \\
\hline DE 2 GW SR sensitivity scenario & & & & & \\
DSM usage & {$[\mathrm{h}]$} & 16 & 144 & 2 & 0 & 81 \\
No market clearing & {$[\mathrm{h}]$} & 0 & 29 & 0 & 0 & 16 \\
Expected load not served & {$[\mathrm{MW}]$} & 0 & 1855 & 0 & 0 & 1097 \\
\hline
\end{tabular}

Table 6 shows the number of hours in which DSM is used and the number of hours in which the wholesale market cannot be cleared. According to these 
figures, also no massive differences to the CRM Policies scenario arise. Thus, the number of hours in which Switzerland has to use DSM for market clearing increased by 2 to 16 as well as the hours in France also increased by 2, whereas the hours in Germany and Austria decreased. The increase in France and Switzerland is due to scarcity in the neighboring countries and therefore, more electricity had to be exported. The number of hours without market clearing in Switzerland, France, and Italy remains at 0. In Germany, the number drops to 29 (from 42 in the CRM Policies scenario). In Austria, the number of hours decline by one to 16 . The decrease in the number of hours of DSM usage and no market clearing in Germany and Austria is mainly due to the fact that more capacity will be available in the years after 2020 and the market can therefore be cleared more often without any support of DSM. The expected energy not served is also declining slightly in Germany but rises slightly in Austria. In summary, this sensitivity confirms the results of the CRM Policies scenario.

\section{Critical reflection}

The scenario analyses presented in this paper are carried out formulating own assumptions or using best available studies for the uncertain input parameters, such as the development of the electricity demand, prices for carbon certificates, and fuel prices for gas or coal. No market data are accessible for a time horizon up to 2050. This is why the EU Reference scenario (European Commission, 2016) is taken as an input source for the investigation. However, this input data are only available in steps of 5 years, so that the intermediate years had to be linearly interpolated. Data about techno- 
logical developments and trends in energy technologies (both conventional and RES) can only be found to a limited extent.

Further simplifications have been made with regard to the electrical grid. The domestic grid is not modeled, neither the transmission nor the distribution grid level, only the interconnector capacities are considered by using NTC values. This means that no grid congestions within a country or other disturbances in the grid are taken into account, but they may play an important role in reality. However, as the study focuses on the balance between supply capacity and demand at the market area scale, the inner-market area bottlenecks play a minor role. In contrast, storage expansion, especially large-scale diffusion of battery storage, can significantly improve generation adequacy but has not been considered in this study. Our approach follows the study by Prognos AG (2012) for Switzerland, which does not envisage any expansion of hydro storage facilities in Switzerland.

Furthermore, some own assumptions had to be made in the CRM modules, as not all market design details are available for all market areas. For instance, in the French capacity market, PowerACE does not differentiate between the obligated parties regarding different demand curve patterns, e.g., for sectors or consumers. Beyond that, the participation of foreign power plants in CRMs is only considered by taking neighboring capacity shares into account in the security margin parameter. Therefore, future research should also focus on further design parameter variations and possible cross-border impacts of alternative designs. 


\section{Conclusions and policy implications}

As generation adequacy is strongly dependent on investments in flexible generation capacity, it is monitored continuously with great scrutiny by regulators. Cross-border effects can strongly influence the investments in neighboring countries and thereby increase or decrease the level of domestic generation adequacy. Thus, it is essential to assess and anticipate these effects.

In this paper, changes in the market design of neighboring countries and, in particular, their effects on a small market area (asymmetric market constellation) are investigated taking the Swiss electricity market as an illustrative example. Switzerland is largely influenced by surrounding electricity markets and needs to analyze the political decisions regarding market design changes and to react to developments in the neighboring countries. The strength of this influence is studied with the help of an agent-based simulation model that is applied to two different scenarios describing possible developments with a time horizon until 2050. The long-term time horizon allows to analyze the generation adequacy not only for the current energy system with a comparably low share of intermittent renewables but also for a time period with very large shares of intermittent sources in the energy system that may not be available when they are needed in peak demand hours. The first scenario assumes energy-only markets (EOMs) in all regarded countries, whereas the second one considers implemented capacity remuneration mechanisms (CRMs) in the neighboring countries, but not in the Swiss market.

In general, the model results indicate a strong price increase in the Central Western European electricity markets, mainly due to rising carbon certificate 
prices and increasing demand. However, the price increase in the CRM Policies scenario is about $27 \mathrm{EUR} / \mathrm{MWh}$ higher in the long term. This is caused by the introduction of national CRMs with high targets for domestic generation adequacy, which lead to overall higher installed capacities in the entire coupled market area. Contrary, in the EOM scenario the capacities are scarce resulting in price peaks.

Regarding the cross-border effects on the country without a CRM, in this case Switzerland, it is shown that higher capacities in the neighboring countries lead to less domestic investments. Therefore in the CRM Policies scenario, the Swiss market can rely on higher imports from the neighboring countries. Hence, Switzerland remains dependent on neighboring countries, although it has a very limited influence on their market design. However, it also turned out that sufficient capacity is available to serve the electricity demand in each time step in both scenarios. The reasons for that are large interconnector capacities and high hydropower capacity in Switzerland. This means that although there is an influence on prices, the generation adequacy in Switzerland is not adversely affected by market design changes in neighboring countries.

Regarding the operational revenues of hydropower plants in the Swiss market, it can be concluded that, as this mainly depends on the development of wholesale electricity prices, the situation is more favorable in the EOM scenario than in the CRM Policies scenario. The EOM scenario produces higher wholesale prices reaching an average annual price of $120 \mathrm{EUR} / \mathrm{MWh}$ in the long term. However, with low operating costs for hydropower and increasing wholesale electricity prices, it is very likely that the hydropower 
plants can be operated profitable independently from the CRM policies in the neighboring countries in future. For this reason and due the fact that generation adequacy is ensured, a change of the Swiss market design is currently not required in any of the investigated scenarios due to changes in other markets.

\section{Acknowledgement}

This study has been conducted in the context a project of the research program "Energy - Economy - Society" (EES), which was funded by the Swiss Federal Office of Energy (SFOE contract number: SI/501308-01). We would like to thank our colleague Joris Dehler as well as Martin Densing and Evangelos Panos from the Energy Economics Group at Paul Scherrer Institute (PSI), who also worked on this project. 


\section{Appendix A. Bidding strategies for hydro storage power plants}

In Switzerland, hydropower accounts for the largest share of electricity generation (Swiss Federal Office of Energy, 2018b). Analyses of the Swiss electricity market require an adequate representation of hydropower plants in an electricity market model. Approximately $16.1 \mathrm{GW}$ of hydropower generation capacity (with a peak demand in 2017 of 10.9 GW (Swiss Federal Office of Energy, 2018c) ) and a total storage capacity of $8.8 \mathrm{TWh}$ (with $62.9 \mathrm{TWh}$ total electricity consumption in 2017 (Swiss Federal Office of Energy, 2018c), see Figure A.12 are available. The hydropower generation capacity (including power plants under construction) is divided into $4.6 \mathrm{GW}$ of run-of-river, $3.1 \mathrm{GW}$ of pumped storage plants and $8.3 \mathrm{GW}$ of seasonal hydro storage plants (Swiss Federal Office of Energy, 2018d).

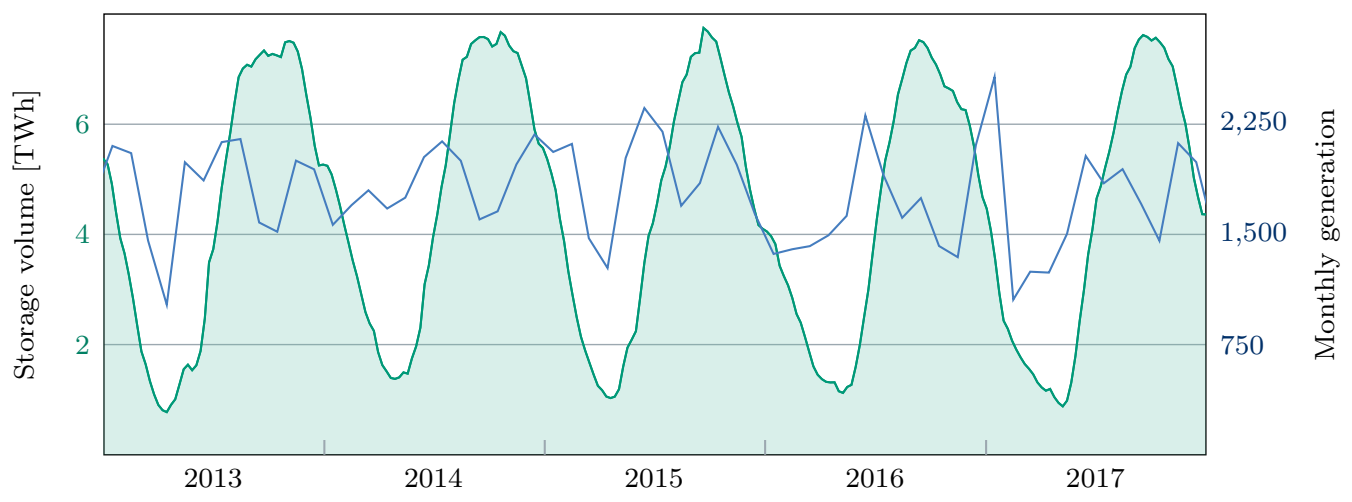

Figure A.12: Historical storage volume (green) and the corresponding monthly generation through water turbines (without pumped storage)

To determine a schedule that maximizes the revenue of seasonal hydropower storages is a complex problem for which different approaches with varying degrees of detail exist (Hongling et al., 2008). In contrast to the 
operation of a thermal power plant that is based on its variable costs, arising mainly from the use of fossil fuels and emission allowances, for storage power plants, the operation depends on opportunity costs, which have to be determined first. As these costs depend on the future development of several uncertain factors, such as weather-dependent inflows, but also on demand and fuel costs (Yakowitz, 1982), both a short-term (days to months) and a medium-term time (one to five years) horizon must be considered (Steeger et al., 2014).

Due to the high share of hydropower in Switzerland, it can be assumed that hydropower does not act as a pure price-taker, but actively influences market prices, which further complicates the determination of an optimal schedule. The combination of the long considered periods of time, the multitude of influencing variables, as well as the fact that the optimal schedule must be determined for every simulated day, lead to the fact that an implementation would exorbitantly increase the computing time of the model. Therefore, different approaches to the hydropower technologies have been applied.

The run-of-river power plants were integrated into the model based on a static generation profile (Swiss Federal Office of Energy (2017) data used from the year 2015) due to the regular values for monthly generation and inflexible production over the years. Meanwhile, the pumped storage plants are modeled as described by (Fraunholz et al., 2017) for an available storage volume of $10 \%$ of the total volume (Swiss Federal Office of Energy (2018c)).

Due to its transparency, a linear regression approach (Equation A.1) is chosen in order to model the seasonal hydropower in Switzerland. This cus- 
tom heuristic, in which an optimal use cannot be guaranteed, but which resembles the historical generation, takes into account the simulated developments, and at the same time only marginally extends the computing time. For this purpose, the hourly historical production time series of seasonal hydro storage power plants from ENTSO-E (2018b) for the years 2015 to 2017 are used for this regression.

The regression was applied for each season of the year $t \mapsto s \in S$ :

$$
\begin{aligned}
\text { hydroGen }_{t}= & \beta_{s}^{0}+\sum_{m}\left(\beta_{m, s}^{\text {load }} \text { load }_{m, t}+\beta_{m, s}^{R E S} R E S_{m, t}\right) \\
& +\sum_{m \neq C H} \beta_{m, s}^{\text {NE }} \text { netExchange }_{C H \rightarrow m, t} \\
& +\sum_{i=1}^{23} \beta_{s}^{i} \text { hour }_{t} \\
& +\beta_{C H, s}^{\text {Storage }} V \\
& +\epsilon_{t}
\end{aligned}
$$

with 


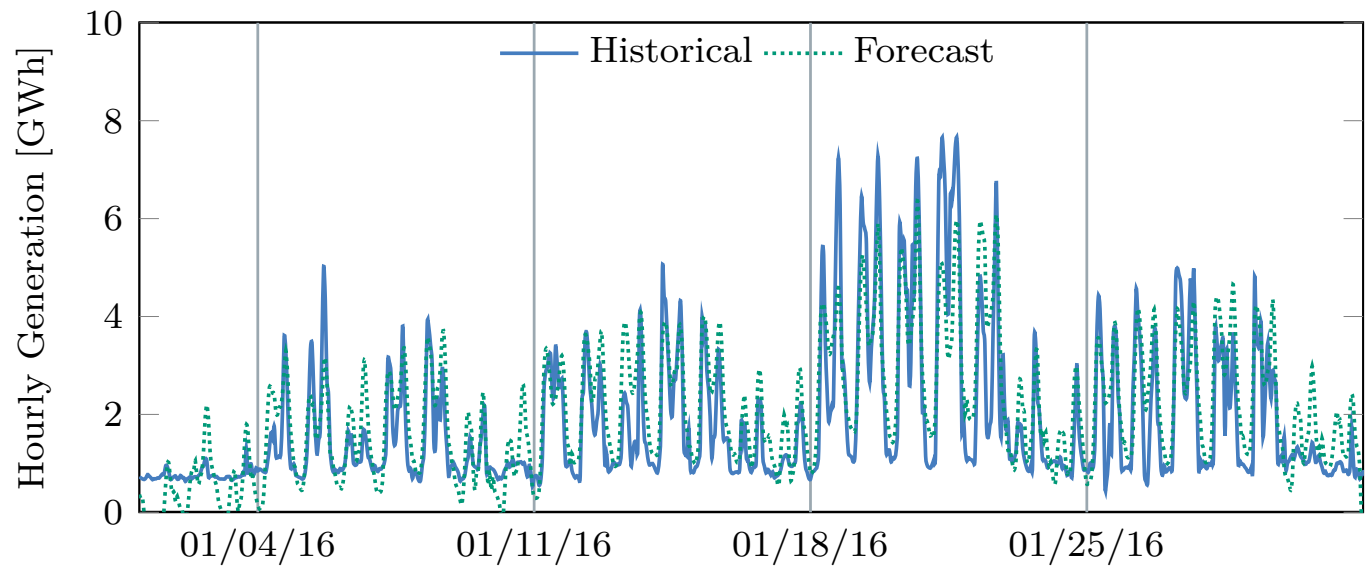

Figure A.13: Operation curves historical and fitted of the seasonal hydro storage power plants.

\section{Parameters}

$\begin{array}{lll}\text { load }_{m, t} & : & \text { Normalized physical load } \\ \text { RES } & : \text { N,t } & \text { Normalized renewable feed-in } \\ \text { netExchange }_{C H \rightarrow m, t} & : & \text { Net electricity exchange between } \\ & & \text { Switzerland and market } m \\ \text { hour }_{t} & : & \text { Dummy for the hour of the day } \\ \text { day }_{t} & : & \text { Dummy for the type of day } \\ V & : & \text { Storage volume in Switzerland }\end{array}$

Sets

$s \subset S \quad:$ Season of the year

$m \in\{A T, C H, D E, F R, I T\}: \quad$ Markets

The following influencing factors are examined with the assessment of the regression: Demand, RES feed-in, weekday or weekend, exchange flows with neighboring market areas, storage level and hour of the day. 
Coefficients for these factors are individually estimated for each season. To account for the increasing capacity of RES, feed-in normalized values (normalized to the total annual production) are used for the variable RES feed-in. Equation A.1 describes the regression model. Table C.7 documents the individual regression coefficients for each season.

The developed regression model and its coefficients are integrated into the agent-based model. Based on the regression model, the hourly operation of the seasonal hydropower plants is calculated. In addition, the storage levels are tracked at any time and in the event of overflow or underrun, the operation is adjusted accordingly. Taken from the model results, Figure A.13 shows the hourly operation in winter simulated with the regression model compared with the real operation. As the values of the regression can also become negative or exceed the possible use, two more limits are introduced (Equation A.2).

$$
\text { hydroGen }_{t}=\min \left\{\text { hydroGen } \max \left\{0, \text { hydroGen }_{t}\right\}\right\}
$$

In addition, further bids will be made to ensure that all the required capacity is available when needed. These are offered at a high price in the market (above the most expensive thermal power plant) so that they are only used in particularly scarce situations and at the same time to ensure that annual generation does not become too high. In order to compare the evolution of the simulated storage in 2016 with the historical storage level, the following is visualized in Figure A.14. 


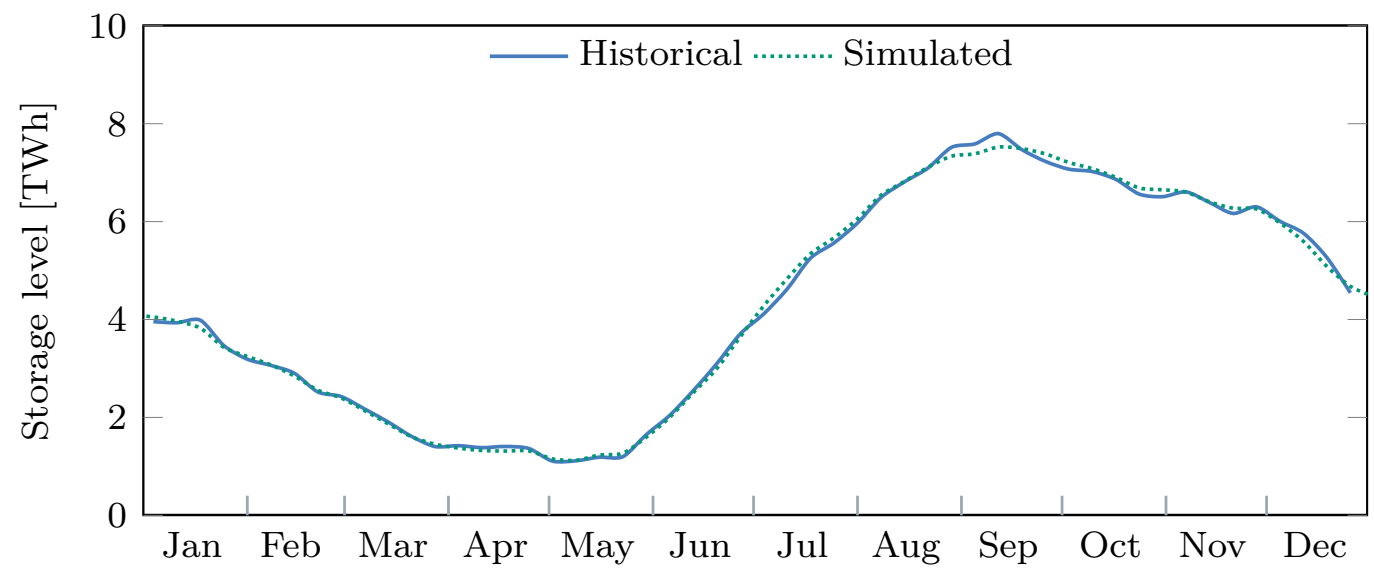

Figure A.14: Level of the stored water in Switzerland's storages historically and in the simulation for the year 2016 


\section{Appendix B. Additional figures}

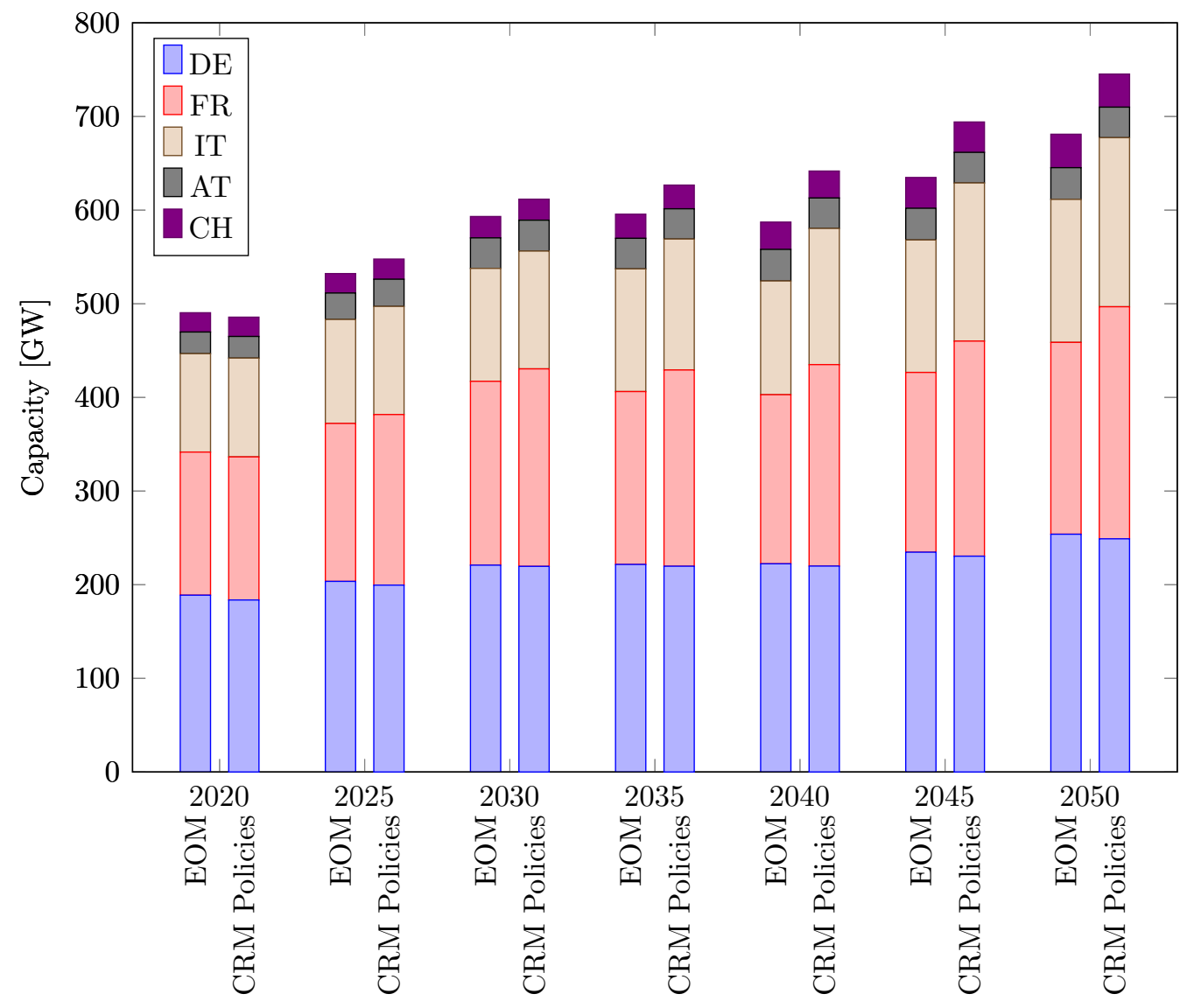

Figure B.15: Total installed capacity in the EOM and CRM Policies scenarios in Switzerland and its neighboring countries. 


\section{Appendix C. Regression results}

Table C.7: The results of the regression model.

\begin{tabular}{|c|c|c|c|c|c|c|c|c|}
\hline & \multicolumn{2}{|c|}{ Spring } & \multicolumn{2}{|c|}{ Summer } & \multicolumn{2}{|c|}{ Autumn } & \multicolumn{2}{|c|}{ Winter } \\
\hline & Estimate & p-Value & Estimate & p-Value & Estimate & p-Value & Estimate & p-Value \\
\hline$\beta^{0}$ & -3055.30 & 0.00 & -2590.32 & 0.00 & -5492.26 & 0.00 & -4413.64 & 0.00 \\
\hline$\beta_{C H}^{\text {Storage }}$ & 0.09 & 0.12 & 0.00 & 0.81 & 0.20 & 0.00 & 0.14 & 0.00 \\
\hline$\beta_{C H}^{\text {lood }}$ & -167.40 & 0.52 & 804.49 & 0.02 & -1277.39 & 0.00 & 1214.66 & 0.00 \\
\hline$\beta_{I T}^{\text {lood }}$ & 1790.62 & 0.00 & 1008.49 & 0.00 & 4910.04 & 0.00 & 3698.31 & 0.00 \\
\hline$\beta_{A T}^{\text {lood }}$ & -50.24 & 0.87 & 1524.15 & 0.00 & -911.18 & 0.00 & -1883.26 & 0.00 \\
\hline$\beta_{F R}^{\text {load }}$ & 286.56 & 0.18 & 2646.13 & 0.00 & 3116.91 & 0.00 & 2425.81 & 0.00 \\
\hline$\beta_{C H}^{\text {lood }}$ & 4499.44 & 0.00 & 1991.39 & 0.00 & 2291.99 & 0.00 & 2667.61 & 0.00 \\
\hline$\beta_{D E}^{R E S}$ & -116.84 & 0.00 & -1021.53 & 0.00 & -247.18 & 0.00 & 62.77 & 0.05 \\
\hline$\beta_{I T}^{R E} S$ & 404.13 & 0.00 & 97.66 & 0.09 & 112.59 & 0.03 & -94.74 & 0.19 \\
\hline$\beta_{A T}^{R E S}$ & -115.73 & 0.10 & 16.22 & 0.79 & -359.64 & 0.00 & -402.61 & 0.00 \\
\hline$\beta_{F R}^{R E S}$ & -647.59 & 0.00 & 1083.81 & 0.00 & -348.66 & 0.00 & -396.45 & 0.00 \\
\hline$\beta_{C H}^{R E S}$ & 165.33 & 0.10 & -1275.55 & 0.00 & 416.83 & 0.00 & -636.80 & 0.02 \\
\hline$\beta^{\text {day }}$ & -138.07 & 0.00 & -168.58 & 0.00 & -132.65 & 0.00 & -32.66 & 0.40 \\
\hline$\beta^{1}$ & -3.81 & 0.96 & 95.52 & 0.23 & 90.69 & 0.24 & -48.47 & 0.58 \\
\hline$\beta^{2}$ & -34.62 & 0.64 & 70.11 & 0.39 & 145.66 & 0.06 & -6.35 & 0.94 \\
\hline$\beta^{3}$ & -74.37 & 0.32 & -65.74 & 0.43 & 57.47 & 0.46 & -0.50 & 1.00 \\
\hline$\beta^{4}$ & -177.28 & 0.02 & -360.92 & 0.00 & -291.58 & 0.00 & -152.46 & 0.09 \\
\hline$\beta^{5}$ & -229.52 & 0.01 & -442.28 & 0.00 & -502.69 & 0.00 & -529.90 & 0.00 \\
\hline$\beta^{6}$ & -7.06 & 0.94 & 168.08 & 0.12 & -404.29 & 0.00 & -617.49 & 0.00 \\
\hline$\beta^{7}$ & -10.04 & 0.92 & 496.31 & 0.00 & -284.82 & 0.00 & -488.87 & 0.00 \\
\hline$\beta^{8}$ & -226.43 & 0.03 & 301.86 & 0.01 & -367.98 & 0.00 & -442.42 & 0.00 \\
\hline$\beta^{9}$ & -545.62 & 0.00 & -19.01 & 0.88 & -506.21 & 0.00 & -433.35 & 0.00 \\
\hline$\beta^{10}$ & -679.40 & 0.00 & -105.21 & 0.39 & -466.28 & 0.00 & -623.01 & 0.00 \\
\hline$\beta^{11}$ & -744.33 & 0.00 & -260.98 & 0.03 & -500.32 & 0.00 & -618.75 & 0.00 \\
\hline$\beta^{12}$ & -870.76 & 0.00 & -432.90 & 0.00 & -715.45 & 0.00 & -783.78 & 0.00 \\
\hline$\beta^{13}$ & -898.47 & 0.00 & -521.07 & 0.00 & -791.37 & 0.00 & -876.77 & 0.00 \\
\hline$\beta^{14}$ & -885.22 & 0.00 & -646.32 & 0.00 & -848.68 & 0.00 & -711.47 & 0.00 \\
\hline$\beta^{15}$ & -821.78 & 0.00 & -762.39 & 0.00 & -862.33 & 0.00 & -666.76 & 0.00 \\
\hline$\beta_{s}^{16}$ & -669.07 & 0.00 & -632.03 & 0.00 & -992.57 & 0.00 & -794.42 & 0.00 \\
\hline$\beta_{s}^{17}$ & -466.30 & 0.00 & -137.89 & 0.18 & -684.73 & 0.00 & -607.35 & 0.00 \\
\hline$\beta_{s}^{18}$ & -31.46 & 0.73 & 398.74 & 0.00 & -60.35 & 0.55 & -382.03 & 0.00 \\
\hline$\beta_{s}^{19}$ & 201.34 & 0.02 & 416.56 & 0.00 & -23.18 & 0.80 & -303.17 & 0.00 \\
\hline$\beta_{s}^{20}$ & 102.08 & 0.21 & 179.67 & 0.05 & -370.24 & 0.00 & -490.31 & 0.00 \\
\hline$\beta_{s}^{21}$ & -26.70 & 0.73 & 225.86 & 0.01 & -338.67 & 0.00 & -495.46 & 0.00 \\
\hline$\beta_{s}^{22}$ & -10.79 & 0.89 & -50.66 & 0.54 & -243.20 & 0.00 & -367.96 & 0.00 \\
\hline$\beta_{s}^{23}$ & -2.43 & 0.97 & 16.93 & 0.83 & -98.09 & 0.20 & -196.59 & 0.03 \\
\hline$\beta_{D E, s}^{N E}$ & -0.32 & 0.00 & -0.11 & 0.00 & -0.37 & 0.00 & -0.32 & 0.00 \\
\hline$\beta_{A T, s}^{N E^{\prime}}$ & -0.52 & 0.00 & -0.05 & 0.23 & -0.70 & 0.00 & -0.26 & 0.00 \\
\hline$\beta_{F R, s}^{N E}$ & -0.30 & 0.00 & -0.14 & 0.00 & -0.27 & 0.00 & -0.44 & 0.00 \\
\hline$\beta_{I T, s}^{N E}$ & -0.24 & 0.00 & -0.09 & 0.00 & -0.38 & 0.00 & -0.28 & 0.00 \\
\hline
\end{tabular}




\section{References}

Bhagwat, P.C., Iychettira, K., de Vries, L.J., 2014. Cross-border effects of capacity mechanisms, in: 2014 11th International Conference on the European Energy Market (EEM), pp. 1-5. doi:10.1109/EEM.2014.6861269.

Bhagwat, P.C., Richstein, J.C., Chappin, E.J., Iychettira, K.K., de Vries, L.J., 2017. Cross-border effects of capacity mechanisms in interconnected power systems. Utilities Policy 46, 33-47. doi:10.1016/j·jup.2017.03. 005 .

BMWi, 2017. Strommarkt der Zukunft. URL: http://www.bmwi.de/ Redaktion/DE/Dossier/strommarkt-der-zukunft.html.

Boffa, F., Pingali, V., Vannoni, D., 2010. Increasing market interconnection: An analysis of the Italian electricity spot market. International Journal of Industrial Organization 28, 311-322. doi:10.1016/j . ijindorg.2009.10. 003.

Bublitz, A., Keles, D., Fichtner, W., 2017. An analysis of the decline of electricity spot prices in Europe: Who is to blame? Energy Policy 107, 323-336. doi $10.1016 /$ j.enpol.2017.04.034.

Bublitz, A., Keles, D., Zimmermann, F., Fraunholz, C., Fichtner, W., 2018. A survey on electricity market design: Insights from theory and real-world implementations of capacity remuneration mechanisms. doi:10.5445/IR/ 1000080063 .

Bublitz, A., Renz, L., Keles, D., Genoese, M., Fichtner, W., 2015. An assessment of the newly proposed strategic reserve in Germany, in: 2015 12th 
International Conference on the European Energy Market (EEM). Lisbon, Portugal, pp. 1-5. doi:10.1109/EEM.2015.7216660.

Cepeda, M., Finon, D., 2011. Generation capacity adequacy in interdependent electricity markets. Energy Policy 39, 3128-3143. doi:10.1016/j . enpol.2011.02.063

Cramton, P., Stoft, S., 2005. A capacity market that makes sense. The Electricity Journal 18, 43-54. doi:10.1016/j.tej.2005.07.003.

Dehler, J., Zimmermann, F., Keles, D., Fichtner, W., 2016. Der Einfluss der Nachbarländer auf den Schweizer Strommarkt, in: 14. Symposium Energieinnovationen, pp. 1-13. URL: https://publikationen. bibliothek.kit.edu/1000052978.

Elberg, C., 2014. Cross-border effects of capacity mechanisms inelectricity markets. URL: http://hdl.handle.net/10419/103414.

ENTSO-E, 2018a. Ten-Year Network Development Plan (TYNDP) 2018. URL: https://www.entsoe.eu/Documents/TYNDP\%20documents/ TYNDP2018/Scenarios\%20Data\%20Sets/Input\%20Data.xlsx.

ENTSO-E, 2018b. Transparency platform. URL: https://transparency. entsoe.eu/.

EPEX SPOT, 2016. EUPHEMIA public description - PCR market coupling algorithm. URL: http://www.epexspot.com/document/36580/16_ 11_28_Euphemia\%20Public\%20Description.pdf.

EPEX SPOT, 2018a. Market data. URL: https://www.epexspot.com/. 
EPEX SPOT, 2018b. Price coupling of regions. URL: http://www. epexspot.com/en/market-coupling/pcr.

Epstein, J.M., 1999. Agent-based computational models and generative social science. Complexity 4, 41-60.

European Commission, 1997. Directive 96/92/EC of the European Parliament and of the Council of 19 December 1996 concerning common rules for the internal market in electricity. Official Journal of the European Union L27, 20-29. URL: http://data.europa.eu/eli/dir/1996/92/oj.

European Commission, 2003. Directive 2003/54/EC of the European Parliament and of the Council of 26 June 2003 concerning common rules for the internal market in electricity and repealing Directive 96/92/EC. Official Journal of the European Union L176, 37-56. URL: http://data.europa. eu/eli/dir/2003/54/oj.

European Commission, 2009. Directive 2009/72/EC of the European Parliament and of the Council of 13 July 2009 concerning common rules for the internal market in electricity and repealing Directive 2003/54/EC. Official Journal of the European Union L211, 55-93. URL: http://data.europa. eu/eli/dir/2009/72/oj.

European Commission, 2016. EU reference scenario 2016: Energy, transport and GHG emissions: trends to 2050. Publications Office, Luxembourg.

European Energy Exchange [EEX], 2011. COSMOS description - CWE market coupling algorithm. 
Finon, D., 2014. Capacity mechanisms and cross-border participation: The EU wide approach in question. URL: http://www.ceem-dauphine.org/ assets/wp/pdf/CEEM_Working_Paper_6_Finon.pdf.

Fraunholz, C., Zimmermann, F., Keles, D., Fichtner, W., 2017. Price-based versus load-smoothing pumped storage operation: Long-term impacts on generation adequacy, in: 2017 14th International Conference on the European Energy Market (EEM), IEEE. pp. 1-6. doi:10.1109/EEM.2017. 7981921.

Glachant, J.M., Rossetto, N., Vasconcelos, J., 2017. Moving the electricity transmission system towards a decarbonised and integrated Europe: Missing pillars and roadblocks. URL: http://hdl.handle.net/1814/46624, doi:10.2870/17199.

Gore, O., Vanadzina, E., Viljainen, S., 2016. Linking the energy-only market and the energy-plus-capacity market. Utilities Policy 38, 52-61. doi:10. $1016 / j \cdot$ jup.2015.12.002.

Guerci, E., Rastegar, M.A., Cincotti, S., 2010. Agent-based modeling and simulation of competitive wholesale electricity markets, in: Rebennack, S., Pardalos, P.M., Pereira, M.V.F., Iliadis, N.A. (Eds.), Handbook of Power Systems II. Springer, Berlin and Heidelberg, pp. 241-286. doi:10.1007/ 978-3-642-12686-4\{\textunderscore\}9.

Hawker, G., Bell, K., Gill, S., 2017. Electricity security in the European Union - The conflict between national capacity mechanisms and the single 
market. Energy Research \& Social Science 24, 51-58. doi:10.1016/j. erss.2016.12.009.

Hirth, L., 2018. What caused the drop in European electricity prices?: A factor decomposition analysis. The Energy Journal 39. doi:10.5547/ 01956574.39.1.1hir.

Hongling, I., Chuanwen, J., Yan, Z., 2008. A review on risk-constrained hydropower scheduling in deregulated power market. Renewable and Sustainable Energy Reviews 12, 1465-1475. doi:10.1016/j.rser.2007.01.018.

ISO New England, 2014. Introduction to New England's forward capacity market. URL: https://wWw.iso-ne.com/static-assets/documents/ 2014/08/iso101-t4-mkt-fcm.pdf.

Kallabis, T., Pape, C., Weber, C., 2016. The plunge in German electricity futures prices - Analysis using a parsimonious fundamental model. Energy Policy 95, 280-290. doi:10.1016/j.enpol.2016.04.025.

Keles, D., Bublitz, A., Zimmermann, F., Genoese, M., Fichtner, W., 2016a. Analysis of design options for the electricity market: The German case. Applied Energy 183, 884-901. doi:10.1016/j . apenergy.2016.08.189.

Keles, D., Renz, L., Bublitz, A., Zimmermann, F., Genoese, M., Fichtner, W., Höfling, H., Sensfuß, F., Winkler, J., 2016b. Zukunftsfähige Designoptionen für den deutschen Strommarkt: Ein Vergleich des Energyonly-Marktes mit Kapazitätsmärkten. volume Band 10 of Produktion und Energie / Karlsruher Institut für Technologie, Institut für Industriebe- 
triebslehre und industrielle Produktion, Deutsch-Französisches Institut für Umweltforschung. KIT Scientific Publishing, Karlsruhe, Baden.

Kraft, E., 2017. Analysis and Modelling of the French Capacity Mechanism: Impact Assessment of Energy Policy Measures on the Security of Supply. BestMasters, Springer Fachmedien Wiesbaden, Wiesbaden. URL: http://dx.doi.org/10.1007/978-3-658-20093-0, doi:10.1007/ 978-3-658-20093-0.

Lorenczik, S., 2017. Essays on market design and strategic behaviour in energy markets. URL: http://kups.ub.uni-koeln.de/id/eprint/7896.

Mastropietro, P., Rodilla, P., Batlle, C., 2015. National capacity mechanisms in the European internal energy market: Opening the doors to neighbours. Energy Policy 82, 38-47. doi:10.1016/j.enpol.2015.03.004.

Meyer, R., Gore, O., 2015. Cross-border effects of capacity mechanisms: Do uncoordinated market design changes contradict the goals of the European market integration? Energy Economics 51, 9-20. doi:10.1016/j. eneco. 2015.06.011.

NEP, 2018. Szenariorahmen für die Netzentwicklungspläne Strom 2030 (Version 2019): Entwurf der übertragungsnetzbetreiber. URL: https://www. netzentwicklungsplan.de/sites/default/files/paragraphs-files/ \%C3\%9CNB-Entwurf_Szenariorahmen_2030_V2019.pdf.

Neuhoff, K., Diekmann, J., Kunz, F., Rüster, S., Schill, W.P., Schwenen, S., 2016. A coordinated strategic reserve to safeguard the European energy transition. Utilities Policy 41, 252-263. doi:10.1016/j.jup.2016.02.002. 
Ochoa, C., Gore, O., 2015. The Finnish power market: Are imports from Russia low-cost? Energy Policy 80, 122-132. doi:10.1016/j.enpol.2015. 01.031 .

Ochoa, C., van Ackere, A., 2015a. Does size matter? Simulating electricity market coupling between Colombia and Ecuador. Renewable and Sustainable Energy Reviews 50, 1108-1124. doi:10.1016/j.rser.2015.05.054.

Ochoa, C., van Ackere, A., 2015b. Winners and losers of market coupling. Energy 80, 522-534. doi:10.1016/j.energy.2014.11.088.

Osorio, S., van Ackere, A., 2016. From nuclear phase-out to renewable energies in the Swiss electricity market. Energy Policy 93, 8-22. doi:10.1016/j.enpol.2016.02.043.

Prognos AG, 2012. Die Energieperspektiven für die Schweiz bis 2050: Energienachfrage und Elektrizitätsangebot in der Schweiz 2000-2050. URL: http://www.bfe.admin.ch/php/modules/publikationen/ stream.php?extlang=de\&name=de_564869151.pdf\&endung=Die\% 20Energieperspektiven $\% 20 f \%$ FCr $\% 20$ die $\% 20$ Schweiz $\% 20$ bis $\% 202050$.

Ringler, P., Keles, D., Fichtner, W., 2017. How to benefit from a common European electricity market design. Energy Policy 101, 629-643. doi:10. 1016/j.enpol.2016.11.011.

RTE, 2017. Mécanisme de capacité. URL: https://clients.rte-france. com/lang/fr/visiteurs/vie/meca_capa/meca_capa.jsp.

Schröder, A., Kunz, F., Meiss, J., Mendelevitch, R., von Hirschhausen, C., 2013. Current and prospective costs of electricity generation until 
2050. URL: https://www.diw.de/documents/publikationen/73/diw_ 01.c.424566.de/diw_datadoc_2013-068.pdf.

Simon, H.A., 1986. Rationality in psychology and economics. The Journal of Business 59, 209-224. URL: http://www . jstor.org/stable/2352757.

S\&P Global Platts, 2016. World electric power plants database. URL: http://www.platts.com/products/ world-electric-power-plants-database.

Steeger, G., Barroso, L.A., Rebennack, S., 2014. Optimal bidding strategies for hydro-electric producers: A literature survey. IEEE Transactions on Power Systems 29, 1758-1766. doi:10.1109/TPWRS.2013.2296400.

Swiss Federal Office of Energy, 2017. Gesamte Erzeugung und Abgabe elektrischer Energie in der Schweiz 2016. URL: http://www.bfe.admin. $\mathrm{ch} / \mathrm{php} / \mathrm{modules} / \mathrm{publikationen/stream} \cdot \mathrm{php}$ ?extlang=de\&name= de_141738330.pdf\&endung=Gesamte $\% 20$ Erzeugung $\% 20$ und $\% 20 \mathrm{Abgabe} \%$ 20 elektrischer $\% 20$ Energie\%20in\%20der $\% 20$ Schweiz $\% 202016$.

Swiss Federal Office of Energy, 2018a. Gesamte Erzeugung und Abgabe elektrischer Energie in der Schweiz 2017. URL: http://www.bfe.admin. $\mathrm{ch} / \mathrm{php} / \mathrm{modules} / \mathrm{publikationen} /$ stream $\cdot \mathrm{php}$ ?extlang=de\&name= de_4326995.pdf\&endung=Gesamte $\% 20$ Erzeugung $\% 20$ und $\% 20$ Abgabe $\%$ 20 elektrischer\%20Energie\%20in\%20der\%20Schweiz $\% 202017$.

Swiss Federal Office of Energy, 2018b. Rentabilität der Schweizer Wasserkraft: Resultate einer Datenumfrage bei Betreibern von Schweizer 
Wasserkraftwerken. URL: http://www.bfe.admin.ch/php/modules/ publikationen/stream.php?extlang=de\&name=de_803246652.PDF.

Swiss Federal Office of Energy, 2018c. Schweizerische Elektrizitätsstatistik 2017. URL: http://www.bfe.admin.ch/php/modules/ publikationen/stream .php?extlang=de\&name=de_893526028.pdf\& endung=Schweizerische\%20Elektrizit\%E4tsstatistik\%202017.

Swiss Federal Office of Energy, 2018d. Statistik der Wasserkraftanlagen der Schweiz. URL: http://www.bfe.admin.ch/php/modules/ publikationen/stream.php?extlang=de\&name=de_496108515.zip\& endung=Statistik\%20der\%20Wasserkraftanlagen $\% 20$ der $\% 20$ Schweiz.

Swissgrid, 2015. Energieübersicht Schweiz 2015. URL: https://www. swissgrid.ch/de/home/operation/grid-data.html.

Tesfatsion, L., 2003. Agent-based computational economics: Modeling economies as complex adaptive systems. Information Sciences 149, 262268. doi:10.1016/S0020-0255(02)00280-3.

Ventosa, M., Baíllo, Á., Ramos, Andrés, Rivier, Michel, 2005. Electricity market modeling trends. Energy Policy 33, 897-913. doi:10.1016/j . enpol.2003.10.013.

Weidlich, A., Veit, D.J., 2008. A critical survey of agent-based wholesale electricity market models. Energy Economics 30, 1728-1759. doi:10.1016/ j.eneco.2008.01.003.

Yakowitz, S., 1982. Dynamic programming applications in water resources. Water Resources Research 18, 673-696. doi:10.1029/WR018i004p00673. 
Zimmermann, F., Keles, D., Fichtner, W., 2017. Agentenbasierte Analyse der Auswirkungen des französischen Kapazitätsmarkts, in: 10. Internationale Energiewirtschaftstagung (IEWT), pp. 1-15. URL: https: //publikationen.bibliothek.kit.edu/1000065978. 


\title{
Working Paper Series in Production and Energy
}

\author{
recent issues
}

No. 32 Daniel Fehrenbach: Modellgestützte Optimierung des energetischen Eigenverbrauchs von Wohngebäuden bei sektor-gekoppelter Wärmeversorgung -Vorstellung des POPART-Modells

Nr. 31 Jann Weinand, Russell McKenna, Katharina Karner, Lorenz Braun, Carsten Herbes: Assessing the potential contribution of excess heat from biogas plants towards decarbonising German residential heating

No. 30 Daniel Heinz: Erstellung und Auswertung repräsentativer Mobilitätsund Ladeprofile für Elektrofahrzeuge in Deutschland

No. 29 Alexander Harbrecht, Russell McKenna, David Fischer, Wolf Fichtner: Behavior-oriented Modeling of Electric Vehicle Load Profiles: A Stochastic Simulation Model Considering Different Household Characteristics, Charging Decisions and Locations

No. 28 Felix Hübner, Sven Möller, Frank Schultmann: Entwicklung eines Expertensystems für die Planung kerntechnischer Rückbauprojekte

No. 27 Andreas Bublitz, Dogan Keles, Florian Zimmermann, Christoph Fraunholz, Wolf Fichtner: A survey on electricity market design : Insights from theory and real-world implementations of capacity remuneration mechanisms

No. 26 Jann Weinand, Russell McKenna, Wolf Fichtner: Developing a municipality typology for modelling decentralised energy systems

No. 25 Felix Hübner, Tobias Hünlich, Florian Frost, Rebekka Volk, Frank Schultmann: Analyse des internationalen Marktes für den Rückbau kerntechnischer Anlagen: Stand und Ausblick

No. 24 Hannes Schwarz, Lars Kotthoff, Holger Hoos, Wolf Fichtner, Valentin Bertsch: Using automated algorithm configuration to improve the optimization of decentralized energy systems modeled as large-scale, two-stage stochastic programs

No. 23 Martin Hain, Hans Schermeyer, Marliese Uhrig-Homburg, Wolf Fichtner: An Electricity Price Modeling Framework for RenewableDominant Markets

The responsibility for the contents of the working papers rests with the author, not the institute. Since working papers are of preliminary nature, it may be useful to contact the author of a particular working paper about results or caveats before referring to, or quoting, a paper. Any comments on working papers should be sent directly to the author. 


\section{Impressum}

Karlsruher Institut für Technologie

Institut für Industriebetriebslehre und Industrielle Produktion (IIP) Deutsch-Französisches Institut für Umweltforschung (DFIU)

Hertzstr. 16

D-76187 Karlsruhe

KIT - Universität des Landes Baden-Württemberg und

nationales Forschungszentrum in der Helmholtz-Gemeinschaft

Working Paper Series in Production and Energy

No. 35, February 2019

ISSN 2196-7296 